\title{
Article \\ Enhancement of the Supercapacitive Performance of Cobalt-tin-cyanate Layered Structures through Conversion from 2D Materials to 1D Nanofibers
}

\author{
Osama Saber ${ }^{1,2, *(\mathbb{D}}$, Sajid Ali Ansari ${ }^{1, *(1)}$ and Abdullah Aljaafari ${ }^{1} \mathbb{D}$ \\ 1 Department of Physics, College of Science, King Faisal University, P.O. Box. 400, Al-ahsa 31982, Saudi Arabia; \\ aaljaafari@kfu.edu.sa \\ 2 Department of Petroleum Refining, Egyptian Petroleum Research Institute, Nasr City, Cairo 11727, Egypt \\ * Correspondence: osmohamed@kfu.edu.sa (O.S.); sansari@kfu.edu.sa (S.A.A.); Tel.: +966-13-589-9440 (O.S.)
}

check for

updates

Citation: Saber, O.; Ansari, S.A.;

Aljaafari, A. Enhancement of the

Supercapacitive Performance of

Cobalt-tin-cyanate Layered Structures

through Conversion from 2D

Materials to 1D Nanofibers. Appl. Sci.

2021, 11, 4289. https://doi.org/

10.3390/app11094289

Academic Editors: Vladimir

M. Fomin and Hyeonseok Yoon

Received: 13 March 2021

Accepted: 4 May 2021

Published: 10 May 2021

Publisher's Note: MDPI stays neutral with regard to jurisdictional claims in published maps and institutional affiliations.

\begin{abstract}
Rational design of the micro-nanomorphology is highly desired for metal hydroxides to achieve overall high-performance electrodes for supercapacitor and energy storage applications. Here, in the current study, we have succeeded in controlling the morphology of Sn/Co nanolayered structures to obtain plate and nanofibrous morphologies. Additionally, the plate nanostructures could be transformed to obtain plate-nanofibrous morphologies. In this trend, dual anions such as cyanate and nitrate are applied to intercalate among the nanolayers of cobalt-tin and act as building blocks or pillars, producing a series of nanolayered structures. By repulsion forces among the intercalated anions, the nanolayers of $\mathrm{Sn} / \mathrm{Co}$ are curled and converted to nanofibers. This conversion was confirmed by scanning electron microscopy. In addition, the intercalation reactions and nanolayered structures were indicated by $\mathrm{X}$-ray diffraction, thermal analyses and Fouriertransform infrared spectroscopy. The electrochemical supercapacitive behavior of the different nanostructures of Sn/Co HDS and Sn/Co LDH, such as plate, Plate-nanofiber and nanofibrous morphology has been investigated in three assembly electrode system. The results suggested that the nanofiber morphology of Sn/Co LDH exhibited better specific capacitance performance than the other two morphologies. The enhanced specific capacitance $\left(658 \mathrm{Fg}^{-1}\right)$ and excellent cyclic stability $(89 \%)$ of the nanofibers of the Sn/Co LDH could be attributed to the synergistic effects between the electric double layer capacitive character of the tin and the pseudocapacitance nature of the cobalt.
\end{abstract}

Keywords: nanofibers; nanolayers; plate-nanofibrous morphology; cyclic voltammetry; cyclic stability; charge-discharge method

\section{Introduction}

Various efforts have been undertaken to solve the energy issue, as the energy required in our daily lives is still totally dependent on fossil fuels, which causes environmental issues. Therefore, various types of the alternative energy windows have been explored in the search to develop an energy storage device which can provide enough power to fulfill our daily living requirements related to energy, as our most of human activities depend on energy. For this purpose, electrochemical abased energy conversion systems have received much attention, especially supercapacitors, which could provide a large amount of power density compared to batteries in short periods of time. Therefore, various efforts have been focused on developing efficient energy devices based on the supercapacitor [1-5]. There are four main parts in the capacitor, including the electrode, which is the most important part of the any energy device [6-10]. The electrode provides the device with the capability to store the charge and provide enough stability during the charge-discharge process. Various materials, such as carbon-based electrode materials, have been used to develop double layer-based supercapacitor devices, whereas metal oxide/hydroxide has been used to develop pseudocapacitive devices. Pseudocapacitive materials have been 
proven to be excellent specific capacitance materials, as their charge storing mechanisms are dependent on the oxidation and reduction processes over the electrode's surface [11,12]. Among all the transition metal oxides, cobalt-based oxide and hydroxide carbonates have received much attention owing to their sufficient electrical conductivity, easy preparation method, controllable morphology, and easy control of the interaction between positively and negatively charged layers during the layer metal hydroxides [1-5].

Layered metal hydroxides consist of a large and familiar group of inorganic compounds which have two branches; layered double hydroxides (LDHs) and hydroxyl double salt (HDS). Similar key structural features are observed for both LDHs and HDS. They consist of positively charged nanolayers and interlayered anions for charge balancing, but their nanolayers' compositions are different. LDHs contain a mixture of divalent and trivalent or tetravalent cations [13-15], while HDS have only divalent cations [16-18].

Recently, because of the high regulation of dominant compositions without the structure transformation of both LDHs and HDS, their wide applications were effective in the field of supercapacitors as battery-type materials. Transition metal carbonate hydroxides are considered promising scalable and effective alternatives with supercapacitive behaviors because of their ability to supply multiple redox activities and their relatively high electrical conductivity.

Though large theoretical specific capacitance values have been observed for the most metal hydroxides, their supercapacitances could be further improved by combining different metal cations into a host. In this trend, by incorporating various metal cations with the mono-metallic-based carbonate hydroxides, more redox reaction sites and higher electrical conductivity were observed for their composites. Thus, eventually, the electrochemical performance of these composites improved because of their synergistic effects $[19,20]$. For example, $\mathrm{CoNiDH}$ and $\mathrm{Co}_{3} \mathrm{O}_{4}-\mathrm{CoNi}-\mathrm{LDH}$ are some of the most auspicious fictional materials for electrochemical applications such as electrocatalysis, Li-ion batteries and supercapacitors $[19,20]$. Apart from these, $\mathrm{NiAl} / \mathrm{LDH}, \mathrm{MnCo} / \mathrm{LDH}$ and $\mathrm{CoNi} / \mathrm{LDH}$ have widely studied with the aim of constructing efficient electrode materials for supercapacitance applications. Thus, double metal hydroxide materials are attracting increased attention in the field of supercapacitor electrode material research. However, their practical utilization is still limited by their relatively poor rate capability and cyclic retention [21]. In recent studies, they have demonstrated that micro-nano morphology and surface area are the key factors affecting the rate capability and long-term cyclic stability of the double metal hydroxide electrode material [22,23].

Thus, several studies are needed to explore the new micro-nanomorphology with large surface area for the double metal hydroxide to resolve the abovementioned issue. In this trend, the current study has tried to develop and enhance the performance of the cobalt supercapacitor electrode materials through designing nanofiber structures for layered metal double hydroxides with new species such as divalent and tetravalent tin. At the same time, it can provide data for the positive effect of the conversion of 2D nanomaterials to 1D nanofibers.

In the present work, a series of different nanostructures of the Sn/Co HDS and Sn/Co LDH materials, such as plate-nanofibers and nanofibrous morphologies have been synthesized by altering the percentage and the oxidation state of the precursor ( $\mathrm{Sn}$ ). The controlling of the morphology has been studied in detail through intercalating dual anions of both cyanate and nitrate anions in the confined space among the Sn/Co nanolayers. Then, the different morphologies leading to a different electrochemical property have been investigated. This study can provide a reference for future studies about morphological control and provide strategies to enhance the performance of supercapacitor electrode materials. Additionally, nanofibers may be useful for designing and fabricating nanodevices. 


\section{Materials and Methods}

\subsection{Preparation of Nanolayered Structures}

Cobalt (II) nitrate hexahydrate $\mathrm{Co}\left(\mathrm{NO}_{3}\right)_{2} \cdot 6 \mathrm{H}_{2} \mathrm{O}$, Tin(II) chloride anhydrous $\mathrm{SnCl}_{2}$ 99.99\%, Tin(IV) chloride $\mathrm{SnCl}_{4}$ 99.99\% and urea $99 \%$ were acquired from Sigma Aldrich.

The first nanolayered structure was cobalt tin hydroxyl double salt (Sn/Co HDS). It consists of divalent cations of cobalt combined with divalent cations of tin. By using urea hydrolysis, cyanate anions were used as pillars to build nanolayered structures of hydroxyl double salts.

Typically, one liter of an aqueous solution of cobalt and tin was prepared through reacting $0.038 \mathrm{~mol} / \mathrm{L}$ of cobalt nitrate $\left[\mathrm{Co}\left(\mathrm{NO}_{3}\right)_{2} \cdot 6 \mathrm{H}_{2} \mathrm{O}\right]$ with $0.0095 \mathrm{~mol} / \mathrm{L}$ of tin chloride $\left(\mathrm{SnCl}_{2}\right)$. The molar ratio of $\mathrm{Co} / \mathrm{Sn}$ was 4 . An appropriate amount of urea $(0.5 \mathrm{~mol} / \mathrm{L})$ was added to the aqueous solution with vigorous stirring. The temperature reaction of the aqueous mixture was kept at $70^{\circ} \mathrm{C}$. The $\mathrm{pH}$ value of the reaction started to gradually increase. After $12 \mathrm{~h}$, the $\mathrm{pH}$ reached 9 and the product was clear in the aqueous medium. After filtration and washing several times in deionized and distilled water, the product was dried under vacuum at room temperature. This sample was coded as CSHDS.

By changing divalent cations of tin to become tetravalent cations, another kind of nanolayered structure was produced. This second nanolayered structure was prepared through dissolving $0.0095 \mathrm{~mol}$ of tin tetrachloride $\left(\mathrm{SnCl}_{4}\right)$ instead of tin chloride $\left(\mathrm{SnCl}_{2}\right)$. Layered double hydroxides Sn/Co LDH was formed through a combination of tetravalent cations of $\mathrm{Sn}^{4+}$ with divalent cations of $\mathrm{Co}^{2+}$. This sample was coded as CSLDH-1.

The third nanolayered structure was prepared through controlling the hydrolysis of urea by increasing the reaction temperature from $70{ }^{\circ} \mathrm{C}$ to $90^{\circ} \mathrm{C}$ in addition to reducing the molar ratio of Co/Sn from 4 to 3 as seen in Table 1. This sample was coded as CSLDH-2.

Table 1. Different percentages and ratios of both cobalt and tin.

\begin{tabular}{ccccc}
\hline Sample & $\begin{array}{c}\text { Cobalt }\left(\mathbf{C o}^{+2}\right) \\
(\mathbf{m o l e})\end{array}$ & $\begin{array}{c}\text { Tin }\left(\mathbf{S n}^{+2}\right) \\
(\mathbf{m o l e})\end{array}$ & $\begin{array}{c}\text { Tin }\left(\mathbf{S n}^{+4}\right) \\
(\mathbf{m o l e})\end{array}$ & $\begin{array}{c}\text { Co/Sn } \\
\text { Molar Ratio }\end{array}$ \\
\hline CSHDS & 0.038 & - & 0.0095 & 4 \\
CSLDH-1 & 0.038 & 0.0095 & & 4 \\
CSLDH-2 & 0.03 & & 0.0095 & 3 \\
\hline
\end{tabular}

\subsection{Physical Characterization}

The crystalline structures of the prepared materials were determined by X-ray diffraction (XRD) spectra which recorded on Rigaku, RINT 2200 Japan using CuKa (filtered) radiation $(\lambda=0.154 \mathrm{~nm})$ between 1.8 and 50 degrees. The functional groups and interlayered anions were recorded through Fourier Transform Infrared Spectroscopy (FT-IR) over the wave number range $400-4000 \mathrm{~cm}^{-1}$, using "Spectrum Two" from PerkinElmer Company. Thermal analyses (differential thermal analysis-DTA; differential thermal gravimetric-DTG; and thermal gravimetric analysis-TGA) of powdered samples up to $800{ }^{\circ} \mathrm{C}$ were carried out at a heating rate of $10{ }^{\circ} \mathrm{C} / \mathrm{min}$ in flow of both nitrogen and air using a Seiko SSC 5200 Japan. The morphology, shape surface and distribution of the samples were directly obtained at room temperature using Scanning Electron Microscopy (SEM) JEOL:JSM-6330F, Tokyo, Japan.

\subsection{Three Assembly Electrochemical Cell Setup and Electrode Preparation}

The electrochemical performance of all the electrodes was examined in three electrode system with $\mathrm{Pt}$ sheet, $\mathrm{Ag} / \mathrm{AgCl}$ electrode used as a reference and counter electrode, respectively. The working electrodes were fabricated using electrode material, activated carbon and PVDF at the mass ratio of 80:10:10 in NMP solvent. Afterward, slurry was coated on the washed $\mathrm{Ni}$ foam current collector with the effective area of $1 \mathrm{~cm}^{2}$ and dried at $80{ }^{\circ} \mathrm{C}$ for $12 \mathrm{~h}$. All electrochemical measurements were carried out in $2 \mathrm{M} \mathrm{KOH}$ aqueous solution using $\mathrm{CV}$ and $\mathrm{CD}$ analysis. 


\section{Results and Discussion}

\subsection{Scanning Electron Microscopy}

The prepared samples were coated with a thin film of platinum to increase the resolution of the images obtained through scanning electron microscopy (SEM). Figure 1 shows SEM images of CSHDS. It indicated that CSHDS has platelike morphology, agreeing with the literature on HDS [24,25]. The perpendicular orientations of the plates formed a porous structure, as shown in Figure 1a. The plates of the sample CSHDS were observed to have fine edges, indicating that it is in the nanoscale. Their plates' thickness is less than $100 \mathrm{~nm}$, as shown in Figure 1c. The HDS structure was formed through decomposition of urea, as shown in the following equation:

$$
\mathrm{NH}_{2} \mathrm{CONH}_{2} \rightarrow \mathrm{NH}_{4}^{+}+\mathrm{CNO}^{-}+\mathrm{H}^{+}+\mathrm{OH}^{-}
$$

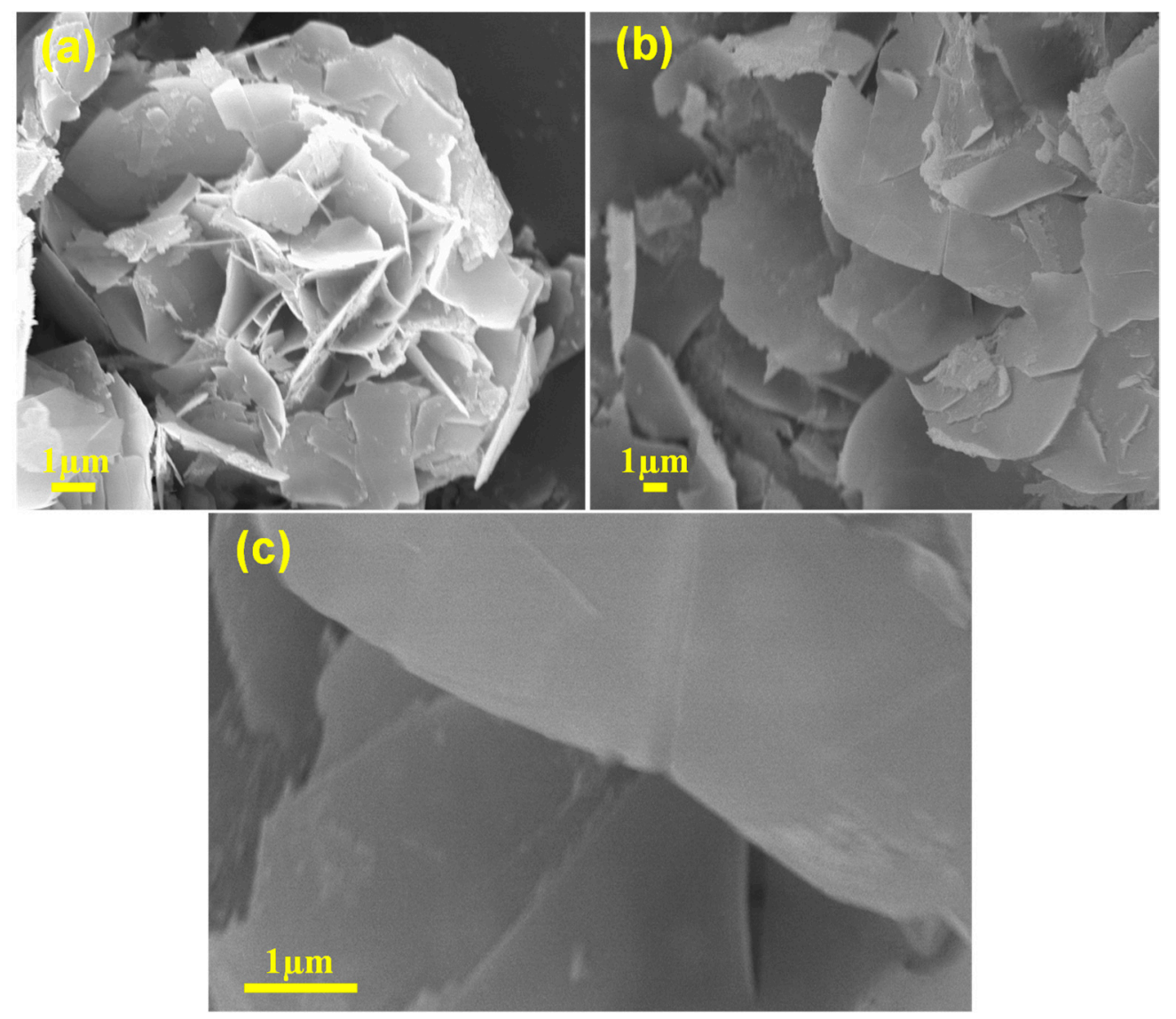

Figure 1. SEM images of CSHDS: (a) First location, (b) second location, and (c) after magnification $\times 10,000$.

According to this equation, the concentration of cyanate gradually increased and the medium of the reaction converted to alkaline with high $\mathrm{pH}$. These conditions are suitable for building a hydroxyl double salt structure. The presence of cyanate anions was confirmed by FT-IR results and EDS spectrum, which will be discussed below.

In the case of CSLDH-1, nanofibers were observed as shown in Figure 2. Figure 2a,b reveal bundles of nanofibers. In addition, individual fibers with diameters of $50 \mathrm{~nm}$ are displayed in Figure 2c. However, the plate morphology is the most famous morphology for the natural samples of layered double hydroxides, which consist of di- and trivalent cations [26]. Figure 2d confirms this speculation through displaying the conversion of $\mathrm{Sn} / \mathrm{Co}$ plates to nanofibers. It shows that the major part of one plate has already transformed to nanofibers and the remaining part of the plate did not convert to nanofibers. 

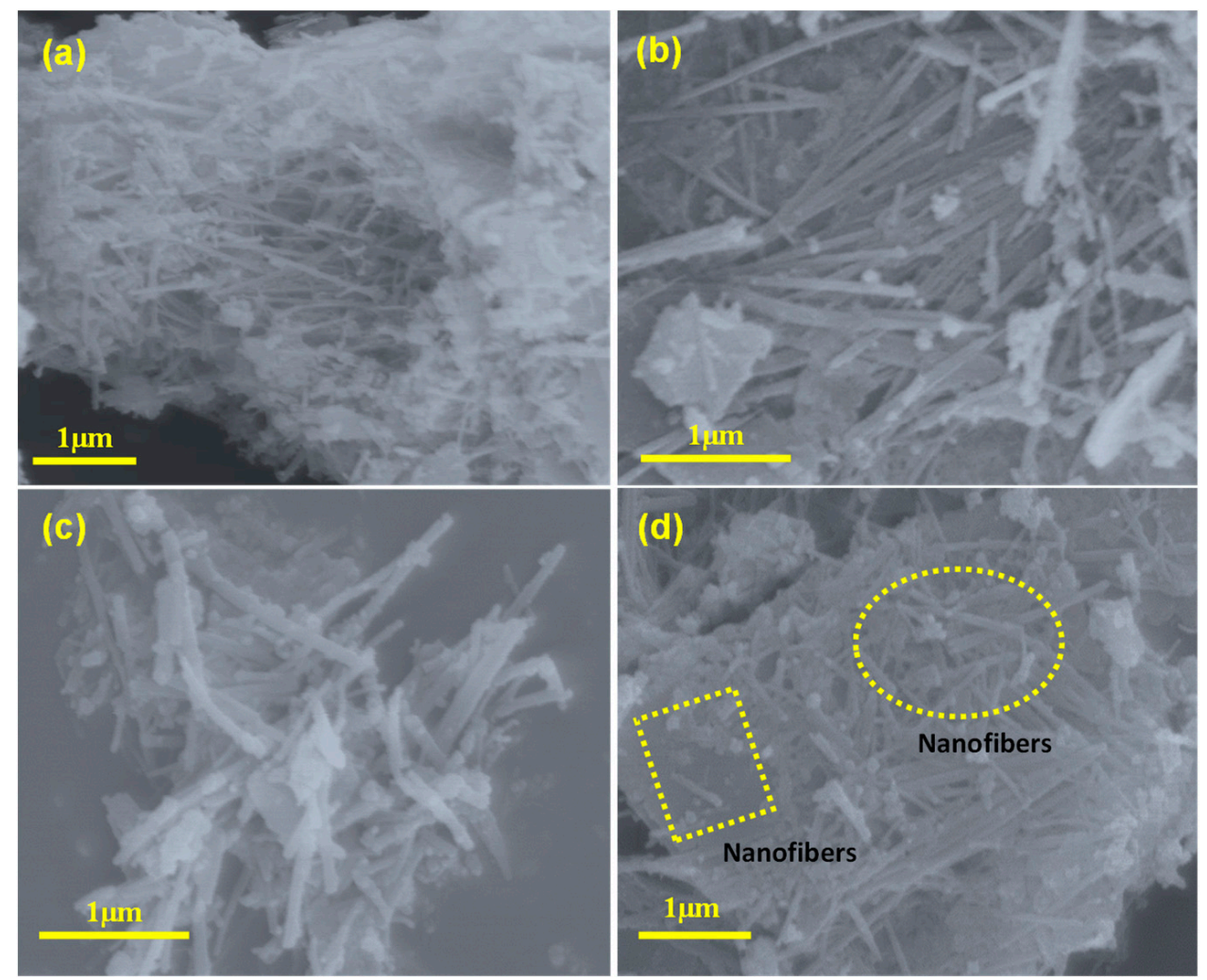

Figure 2. SEM images of CSLDH-1 at different locations.

Energy dispersive X-ray spectrum analysis (EDS) of CSLDH-1 provides local information of the concentrations of the different elements in the outermost layers of the nanofibers. Cobalt and tin were observed in the EDS spectrum with similar percentages for the starting salts. In addition, carbon, oxygen and nitrogen are clearly identified in the nanofibers, as shown in Figure 3. It means that EDS spectrum of CSLDH-1 confirmed the presence of cyanate anions as interlayered anions in addition to traces of nitrate anions because the ratio between carbon and nitrogen in the cyanate anions equal one.

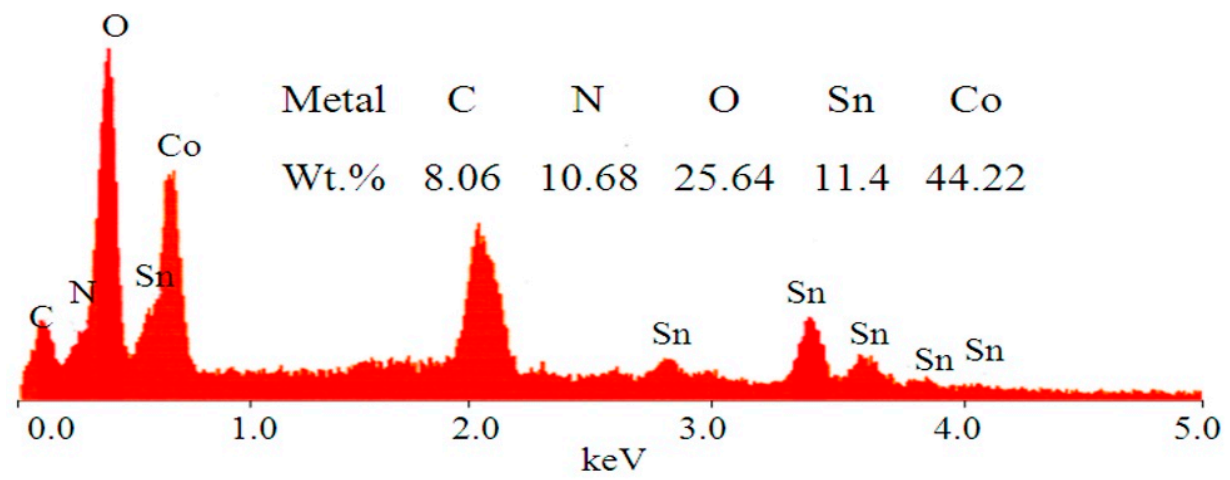

Figure 3. Energy dispersive X-ray spectrum of CSLDH-1.

The nanofibrous morphology of the sample CSLDH-1 could be explained through presence of tetravalent cations of Sn beside divalent cations of Co inside the nanolayers which created positive charges ( +2$)$. During the decomposition of urea, the concentration of cyanate anions increased and the medium of the reaction became rich in cyanate anions. Therefore, dual cyanate anions intercalated among the cationic layers through one side to neutralize the positive charges. The steric hindrance and repulsion between the bulk cyanate anions caused the distortion or curvature of the nanolayers of Sn/Co LDHs. This distortion or curvature led to the formation of nanofibers. 
By increasing the content of tin in the sample CSLDH-2, the positive charges increased in the nanolayers and the amount of interlayered anions accordingly increased, causing more distortion and strong curvature for the layers and producing clear nanofibers because of the repulsion forces among the dual anions. Figure 4 shows that the sample CSLDH-2 has clear nanofibers, confirming this speculation. The diameter of these nanofibers was less than 100 nm, as shown in Figure 4b,c.
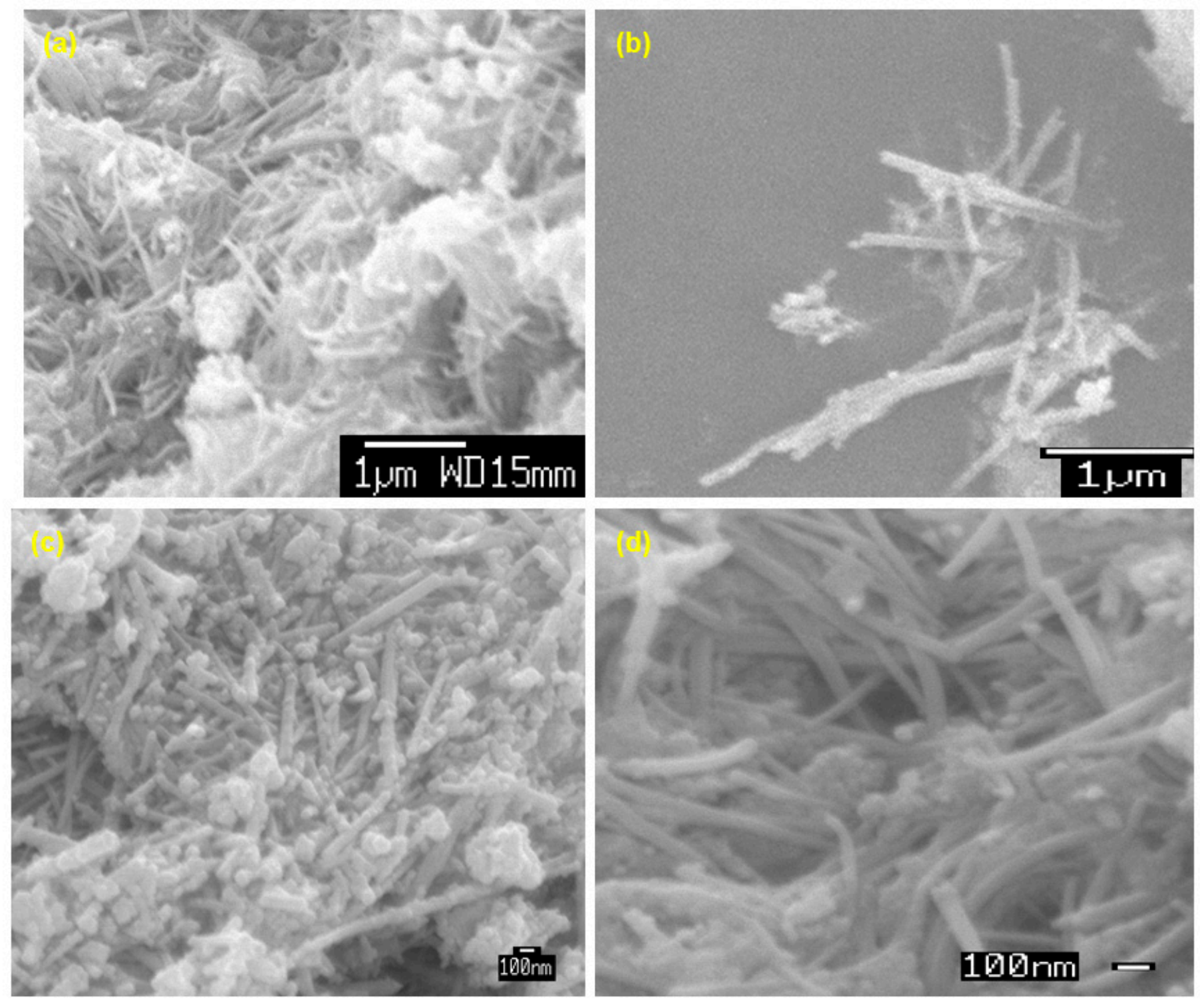

Figure 4. SEM images of CSLDH-2 at different locations.

\subsection{Powder X-ray Diffraction}

X-ray Diffraction (XRD) was used to analyze the phase composition and crystal structure of the prepared materials. Figure 5a shows the XRD pattern of the sample CSHDS. The XRD pattern of CSHDS is typical of layered materials, showing sharp symmetric reflections at a low angle with interlayered spacing $(0.78 \mathrm{~nm})$ and weak asymmetric reflections at high angles with interlayered spacing $(0.39 \mathrm{~nm}$ and $0.268 \mathrm{~nm})$. The good agreement between these values corresponding to successive diffractions by planes, i.e., $0.78 \mathrm{~nm}=2 \times 0.39 \mathrm{~nm}=3 \times 0.268 \mathrm{~nm}$, reveals nanolayered structures with highly packed stacks of HDS layers. Although there are no XRD results reported in the literature for cobalt-tin-cyanate HDS, these diffraction peaks are in agreement with the cobalt nickel 
carbonate hydroxide hydrate phase found using JCPDS card number 40-216. For nanolayered hydroxyl double salt structures, the main peaks observed at $0.78 \mathrm{~nm}, 0.39 \mathrm{~nm}$, and $0.268 \mathrm{~nm}$, which are agreement with the diffraction of the basal planes-(003), (006), and (009), respectively. In addition, the non-basal reflection at $0.299 \mathrm{~nm}$ was considered to be relative to the (100) plane. The value for the (003) peak at $0.78 \mathrm{~nm}$ is slightly larger than the value reported for cobalt nickel hydroxyl double salt, whose value is $0.76 \mathrm{~nm}$ in the case of the carbonate anion as the guest and the cobalt combined with nickel $[20,27]$. This value depends on the size of the anion. This shift from $0.76 \mathrm{~nm}$ to $0.78 \mathrm{~nm}$ suggests the presence of cyanate or nitrate anions instead of carbonate in addition to the incorporation of tin instead of nickel in the lattice of hydroxyl double salts [28,29].

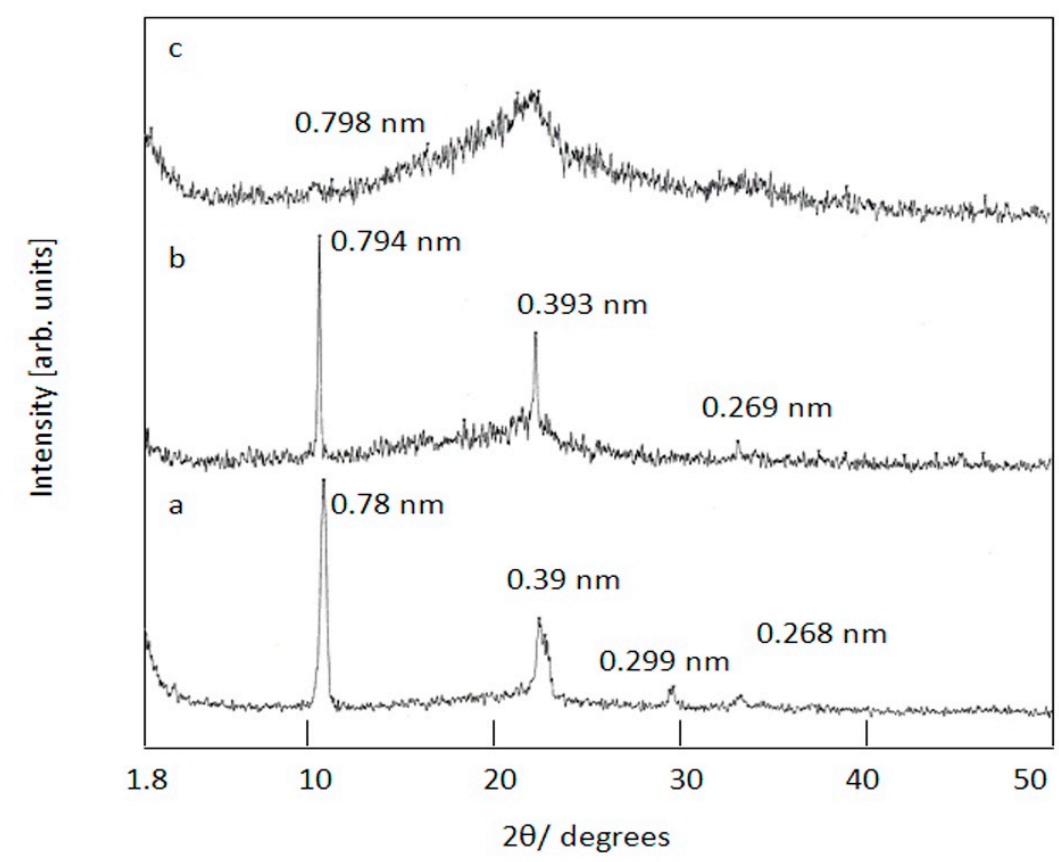

Figure 5. X-ray diffraction of (a) CSHDS, (b) CSLDH-1, and (c) CSLDH-2.

By changing tin from a divalent element to tetravalent element, different kind of layered structures were observed, as shown in Figure 5b. The XRD pattern of the sample CSLDH-1 showed three peaks at spacing $0.794 \mathrm{~nm}, 0.393 \mathrm{~nm}$, and $0.269 \mathrm{~nm}$. This pattern showed strong and sharp peaks at low $2 \Theta$ and weak peaks at high $2 \Theta$, indicating some common features of the layered structures. For layered double hydroxides (LDHs), hydrotalcitelike materials, the reflections of the main planes (003), (006), and (009) agree with the observed peaks at spacing $0.794 \mathrm{~nm}, 0.393 \mathrm{~nm}$, and $0.269 \mathrm{~nm}$, respectively. However, the value of the reflection of the main plane (003) which was observed at $0.79 \mathrm{~nm}$, is significantly larger than the value reported for natural hydrotalcite, whose value is $0.76 \mathrm{~nm}$ in the case of the carbonate anion as the guest [30,31]. This value depends on the size and the orientation of the anion in addition to the thickness of the brucitelike layers $(0.48 \mathrm{~nm}$ for hydrotalcite). This means that the interlayered spacing is not compatible with the size of carbonate anion suggesting presence of cyanate or nitrate anions.

In case of the sample CSLDH-2, the main peaks of the layered structure became opaque. Figure $5 \mathrm{c}$ shows that CSLDH-2 has a non-crystalline structure because of the high content of tetravalent tin, leading to presence of high positive charges inside the nanolayers of the LDHs. It means that the high positive charges caused high concentrations of anions among the nanolayers, leading to high distortion and more curvature for the nanolayers of LDHs. Therefore, the peaks of the XRD became opaque and the nanofibers became clearer in SEM images, which was discussed above. However, the weak peak observed at spacing $0.798 \mathrm{~nm}$ indicates presence of layered double hydroxide in a distortion state. 
According to the SEM images and X-ray results, the transformation of nanolayered materials to nanofibers can be explained through schematic representation in Figure 6. From the known layer thickness, $0.48 \mathrm{~nm}$, and the size of cyanate anion, $0.34 \mathrm{~nm}$, the interlayer spacing available for the anion was calculated as $0.31 \mathrm{~nm}$. It was considered that the cyanate anions have bulk groups having high electron density (e.g., cyanide group with triple bond). Additionally, the size of the nitrate molecules is $0.28 \mathrm{~nm}$ having high electron density. The intercalation of the dual molecules of cyanate anions or nitrate anion among the nanolayers to neutralize the positive charges causes steric hindrance for the nanolayers. Therefore, the repulsion forces among the cyanide groups or nitrate groups led to the nanolayers curling, thereby converting the nanolayers to nanofibers, as shown in Figure 6.

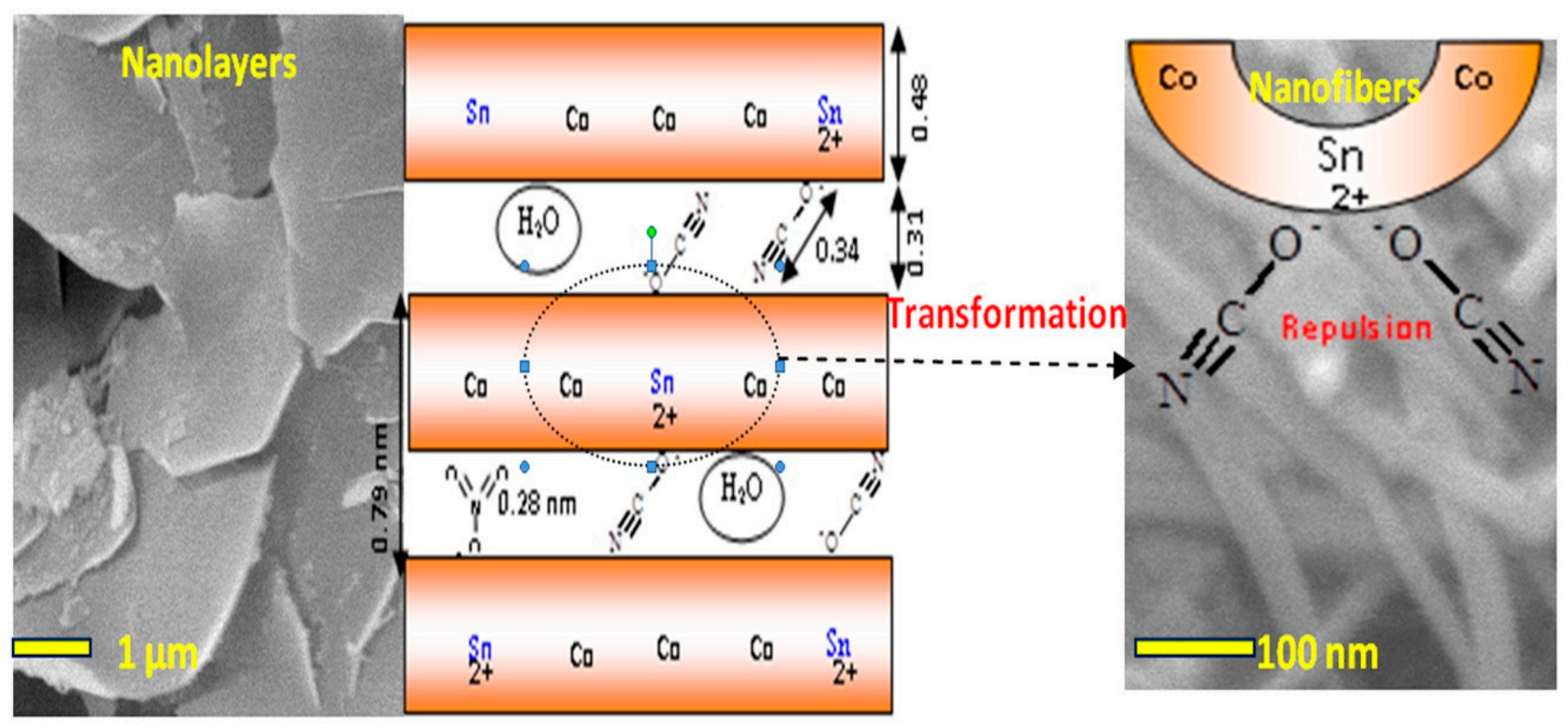

Figure 6. Schematic representation for transformation of nanolayers to nanofibers.

\subsection{Fourier-Transform Infrared Spectroscopy}

The nature and symmetry of functional groups of CSHDS, CSLDH-1 and CSLDH-2 have been identified by the FT-IR technique, as shown in Figure 7. Figure 7a shows the spectrum of CSHDS. The interlayered anions of CSHDS were confirmed by the appearance of a clear band at $2206 \mathrm{~cm}^{-1}$ corresponding to the vibrational mode of cyanate $\left(\mathrm{N} \equiv \mathrm{C}-\mathrm{O}^{-}\right)$.

Small two bands were observed at $1388 \mathrm{~cm}^{-1}$ and $1461 \mathrm{~cm}^{-1}$, indicating that small amounts of nitrate anions were intercalated among the nanolayers [31,32]. Hydroxyl groups of CSHDS were also detected by a broad band at $3423 \mathrm{~cm}^{-1}$. This broadness is due to the hydrogen bonds of the hydroxyl groups. These hydrogen bonds were confirmed by the sharp and strong bands around $2923 \mathrm{~cm}^{-1}$ because the molecules of the interlayered water which hydrogen-bonded to the interlayered anions caused the stretching mode for the $\mathrm{O}-\mathrm{H}$ bands [33]. Additionally, the water molecules exhibited the bending mode band close to $1637 \mathrm{~cm}^{-1}$ [28,32]. 


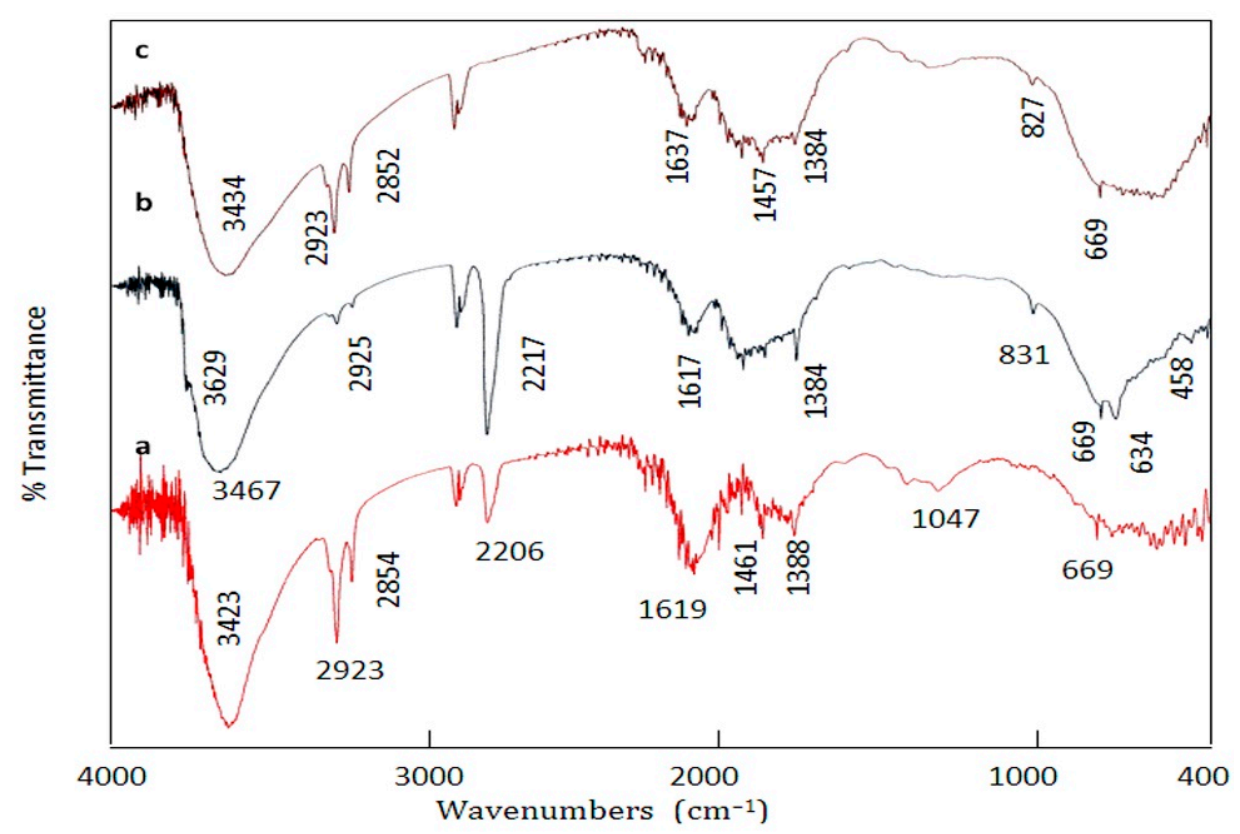

Figure 7. FT-IR spectra of: (a) CSHDS, (b) CSLDH-1, and (c) CSLDH-2.

In the case of CSLDH-1, Figure $7 \mathrm{~b}$ shows a strong band at $2217 \mathrm{~cm}^{-1}$, which was formed due to symmetrical vibration $v_{1}$ of NCO. Additionally, the clear peak observed at $634 \mathrm{~cm}^{-1}$ could be attributed to the $v_{2}$ form of cyanate ion. An important phenomenon is observed for the existence of $\mathrm{NCO}$ ions inside the interlayers beside $\mathrm{OH}$ groups [33]. It revealed that there is a strong effect of the electron density of NCO on the vibration of the $\mathrm{OH}$ groups. The broad $\mathrm{OH}$ vibration band which resolved into two bands was ascribed to the existence of the $\mathrm{NCO}$ group beside the $\mathrm{OH}$ groups. The unaffected $\mathrm{OH}$ groups showed an absorption band at $3629 \mathrm{~cm}^{-1}$, as reported for the usual hydroxyl groups. Additionally, there is another band which was observed at a lower value of $3467 \mathrm{~cm}^{-1}$. The shifting of the band of the hydroxyl group was due to the lowering of the $\mathrm{O}-\mathrm{H}$ bond electron density because of the effect of the cyanide group. This phenomenon is in agreement with the results of $\mathrm{Xu}$ et al. [34] that indicated the outcome of the existence of nitrate ions on the bands of LDH. The shoulder peaks recorded at $2925 \mathrm{~cm}^{-1}$ indicate the stretching $\mathrm{OH}$ bonds that are due to the interlayer water molecules and/or produced from the hydrogen bonds formed with cyanate ions $[15,26,35,36]$. The peak at $1617 \mathrm{~cm}^{-1}$ was due to the bending band of the water molecules [37]. Additionally, the weak peaks observed at both $1457 \mathrm{~cm}^{-1}$ and $1384 \mathrm{~cm}^{-1}$ indicated that there are traces of nitrate as secondary anions.

Figure 7c showed that the sample CSLDH-2 has the main bands of LDH's structure in the case where the guests are nitrate anion. Clear bands for nitrate anions were observed at $1384 \mathrm{~cm}^{-1}$ and $1457 \mathrm{~cm}^{-1}$. Additionally, the hydroxyl band and water band were observed at $3434 \mathrm{~cm}^{-1}$ and $1637 \mathrm{~cm}^{-1}$. The hydrogen bonds were confirmed by strong bands at $2923 \mathrm{~cm}^{-1}$ and $2852 \mathrm{~cm}^{-1}$, indicating that the nitrate anions bonded with hydroxyl groups through H-bonds.

\subsection{Thermal Analyses}

The thermal analyses (differential thermal analysis-DTA; differential thermal gravimetric-DTG; and thermal gravimetric analysis-TGA) of the prepared materials were measured in the presence of both nitrogen gas and air to indicate the oxidation reactions of the divalent cations (cobalt and tin) and the cyanate anions. Figure 8a shows the thermal analyses of CSHDS in the presence of nitrogen. The TGA curve shows the total weight loss that occurred throughout the two stages. 


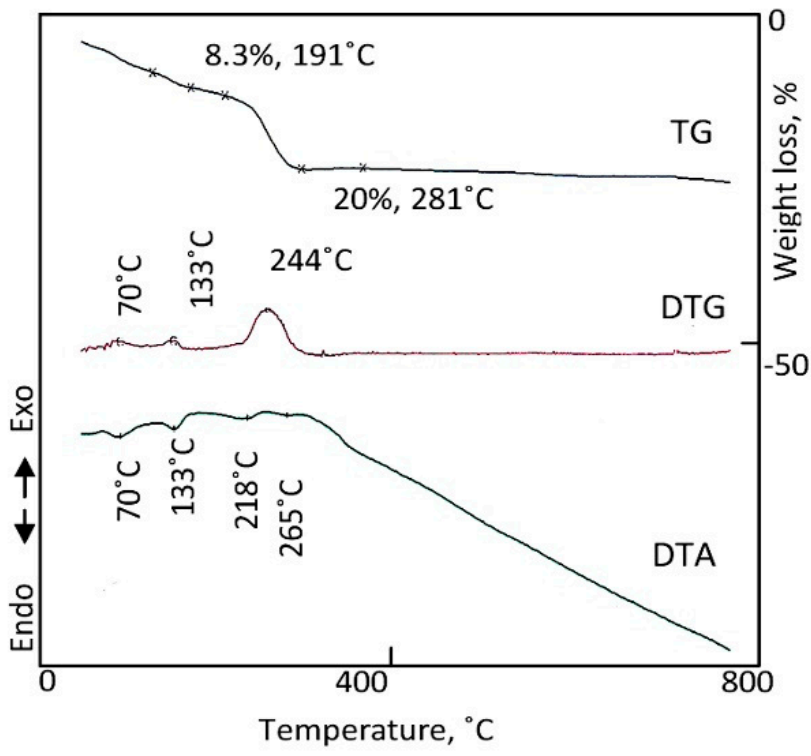

(a)

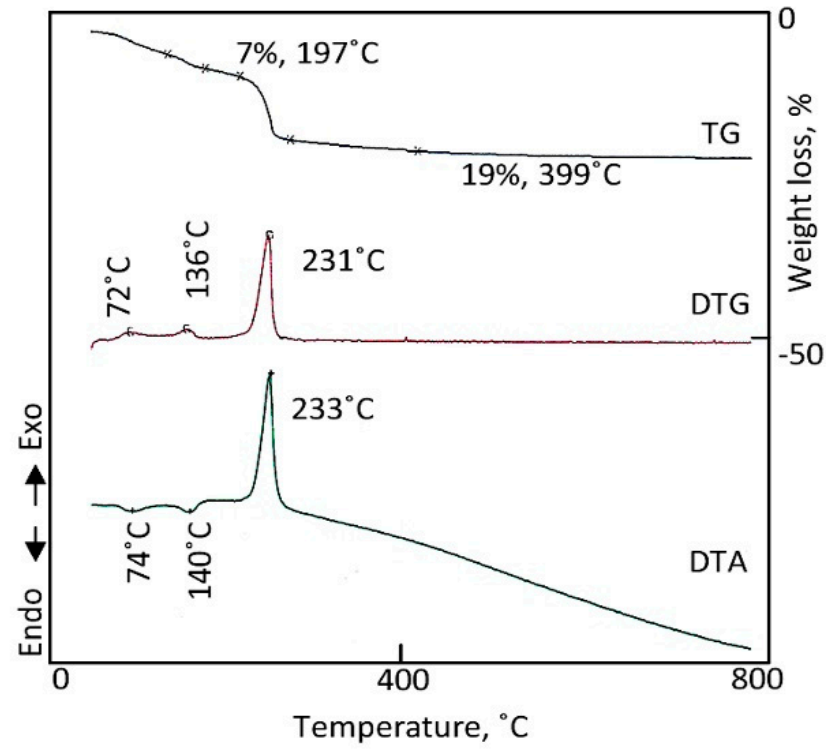

(b)

Figure 8. Thermal analyses of CSHDS in presence of: (a) nitrogen gas and (b) air.

In the first stage, the water was lost through three steps [38]. It was found that $4.6 \mathrm{wt} . \%$, $7 \mathrm{wt} . \%$ and $8.3 \mathrm{wt} . \%$ were lost at $107^{\circ} \mathrm{C}, 150^{\circ} \mathrm{C}$ and $191{ }^{\circ} \mathrm{C}$, respectively. These losses were confirmed by DTG and DTA. DTA showed two endothermic peaks at $70^{\circ} \mathrm{C}$ and $133^{\circ} \mathrm{C}$. It means that the water molecules are bonded in the lattice by two different species-nitrate and cyanate anions $[14,15]$. In the second stage, $11.7 \mathrm{wt} . \%$ was lost, indicating the removal of the interlayered anions at $281^{\circ} \mathrm{C}$. The thermal decomposition of the interlayered anions was confirmed by two endothermic peaks at $218{ }^{\circ} \mathrm{C}$ and $265^{\circ} \mathrm{C}$ in the DTA curve. It means that there are two anions in the lattice of CSHDS.

By measuring the thermal analyses in presence of oxygen, Figure $8 \mathrm{~b}$ showed a strong exothermic peak in DTA curve of CSHDS indicating oxidation reactions of cobalt and tin in addition to cyanate anions at $233^{\circ} \mathrm{C}$. In addition, the two endothermic peaks of water removal were also observed at $74^{\circ} \mathrm{C}$ and $140^{\circ} \mathrm{C}$. The TGA and DTG curves in presence of oxygen showed similar diagrams to that in nitrogen gas, confirming the presence of two anions and intercalated water in the lattice of CSHDS.

The thermal characteristics of the second sample, CSLDH-1 in nitrogen gas, were determined by DTA, DTG and TGA, as shown in Figure 9a. The total weight loss occurred through four steps, indicating removal of surface water, interlayered water, cyanate anions and nitrate anions, respectively $[14,15]$. The DTG curve showed clear two peaks for the removal of the interlayered anions. Additionally, DTA revealed two endothermic peaks at $250.6{ }^{\circ} \mathrm{C}$ and $307.9{ }^{\circ} \mathrm{C}$, confirming the presence of two interlayered anions, cyanate and nitrate, agreeing with the FTIR data.

The different thermal processes of the sample CSLDH-1 are clearly distinguished when its thermal analyses are carried out in presence of air, as shown in Figure 9b. Figure 9b shows that TGA curve of CSLDH-1 has five weight losses with the different slopes indicating the removal of surface water, the removal of interlayered water, the oxidation of cyanate, the oxidation of nitrate and the dehydroxylation process. The DTG curve indicated the oxidation of both cyanate and nitrate anions through two peaks at $231^{\circ} \mathrm{C}$ and $257^{\circ} \mathrm{C}$, respectively. Additionally, the oxidation reactions were confirmed by a strong exothermic peak at $236{ }^{\circ} \mathrm{C}$ in addition to weak peak at $270{ }^{\circ} \mathrm{C}$. 


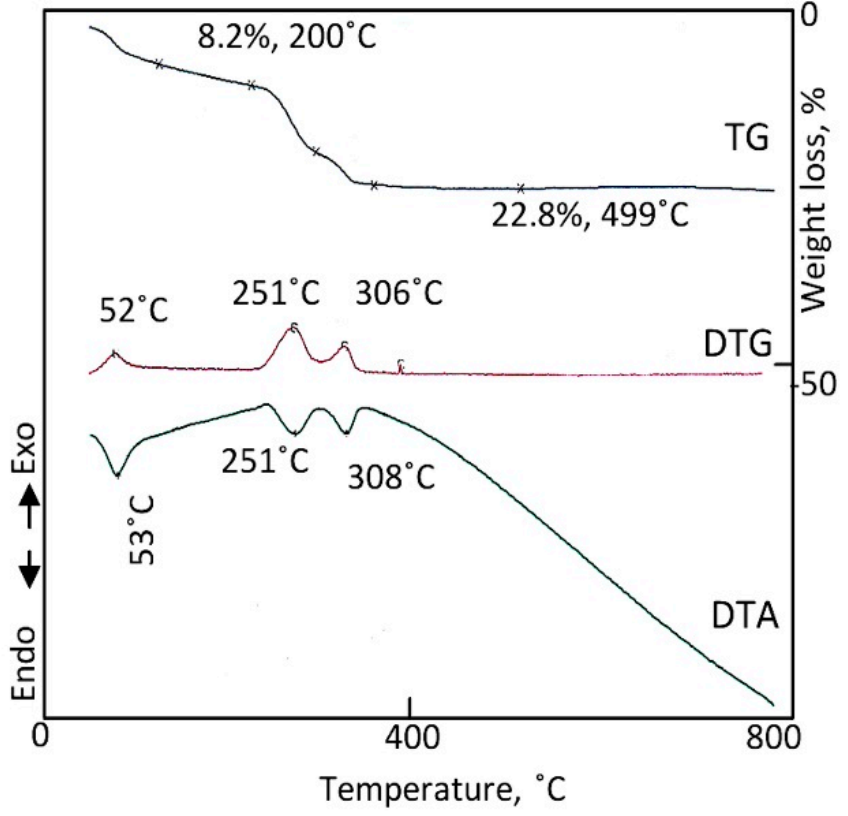

(a)

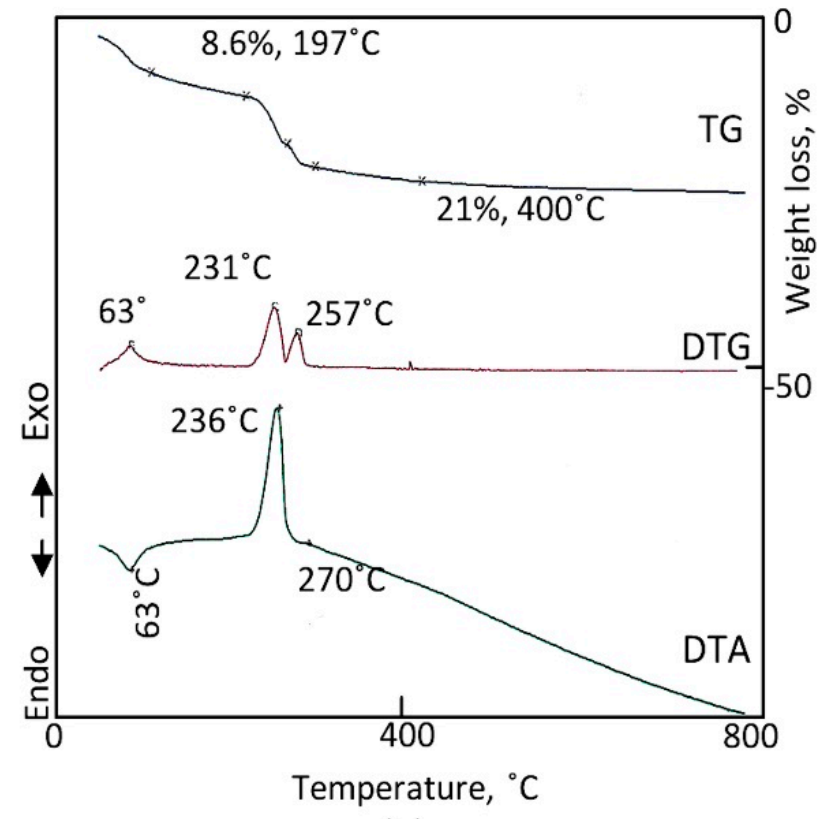

(b)

Figure 9. Thermal analyses of CSLDH-1 in presence of: (a) nitrogen gas and, (b) air.

In the case of CSLDH-2, Figure 10a shows the thermal analyses in the presence of nitrogen gas. Three weight losses were observed in the TGA curve, indicating the existence of one kind of the interlayered anions agreeing with FTIR data. Figure 10a shows that $9 \mathrm{wt.} \%$ of surface water was lost at $99{ }^{\circ} \mathrm{C}$ and $6.2 \mathrm{wt} . \%$ of the interlayered water was removed at $231^{\circ} \mathrm{C}$ [39]. In addition, $5.2 \mathrm{wt} . \%$ of nitrate anions were lost at $321{ }^{\circ} \mathrm{C}$. DTG and DTA confirmed the presence of one kind of anions through one peak at $263^{\circ} \mathrm{C}$ and $269^{\circ} \mathrm{C}$, respectively. In presence of air, these three weight losses were clearly observed in Figure 10b through TG and DTG diagrams. These peaks were confirmed by three endothermic peaks in DTA curve at $57^{\circ} \mathrm{C}, 165^{\circ} \mathrm{C}$ and $247^{\circ} \mathrm{C}$.

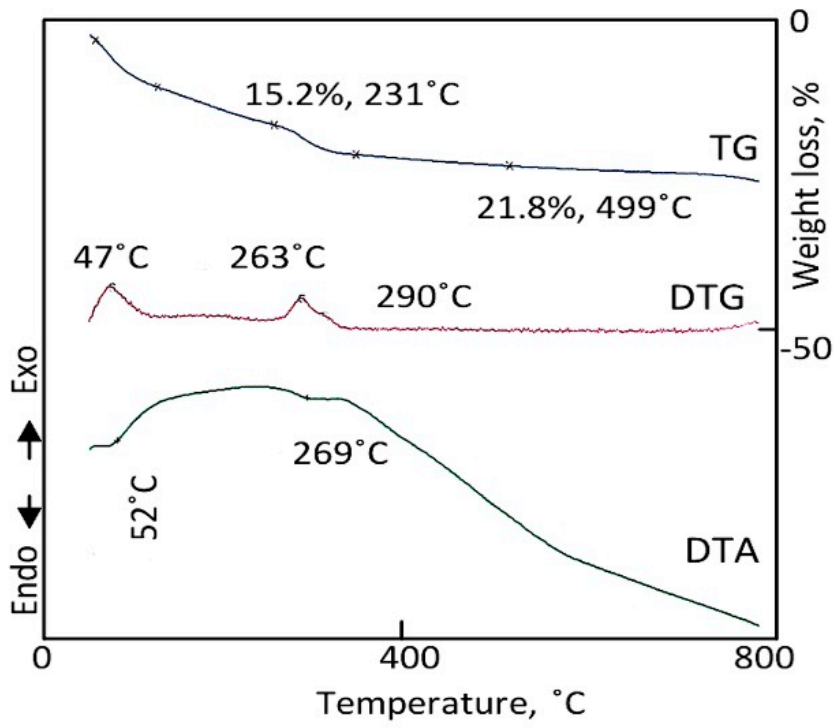

(a)

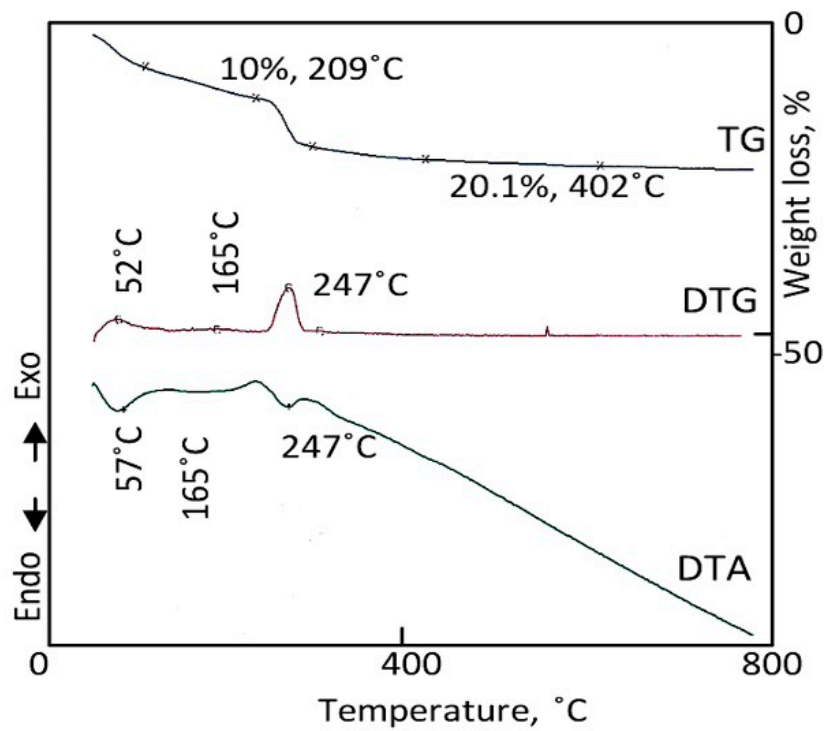

(b)

Figure 10. Thermal analyses of CSLDH-2 in presence of: (a) nitrogen gas and (b) air. 


\subsection{Electrochemical Performance of CSLDH Electrode}

The electrochemical performance is strongly known to depend on the apparent morphology and structure of the material. The microstructure (nanostructured) of the surface of the electrode delivers a high surface area to the electrode materials, which are advantageous for the higher intercalation phenomena of the electric charges and hence, improved the performance owing to the high exchange of ions in electrode materials. The amount/percentage and oxidation state of the precursor alters the surface morphology, and these morphology changes affect the electrochemical properties of the electrode materials. Therefore, to understand the morphological effect of fabricated Sn/Co HDS and Sn/Co LDHs on the electrochemical response and to find out the optimized high performance condition for the electrode preparation in present study, we carried out cyclic voltammetry $(\mathrm{CV})$ and galvanostatic charge-discharge (CD) measurement investigation in a three electrode system (Figures 11 and 12). These measurements are the most prominent tools for assessing the capacitive behavior of the electrodes. All the measurements were performed in a $2 \mathrm{M} \mathrm{KOH}$ electrolytic solution.
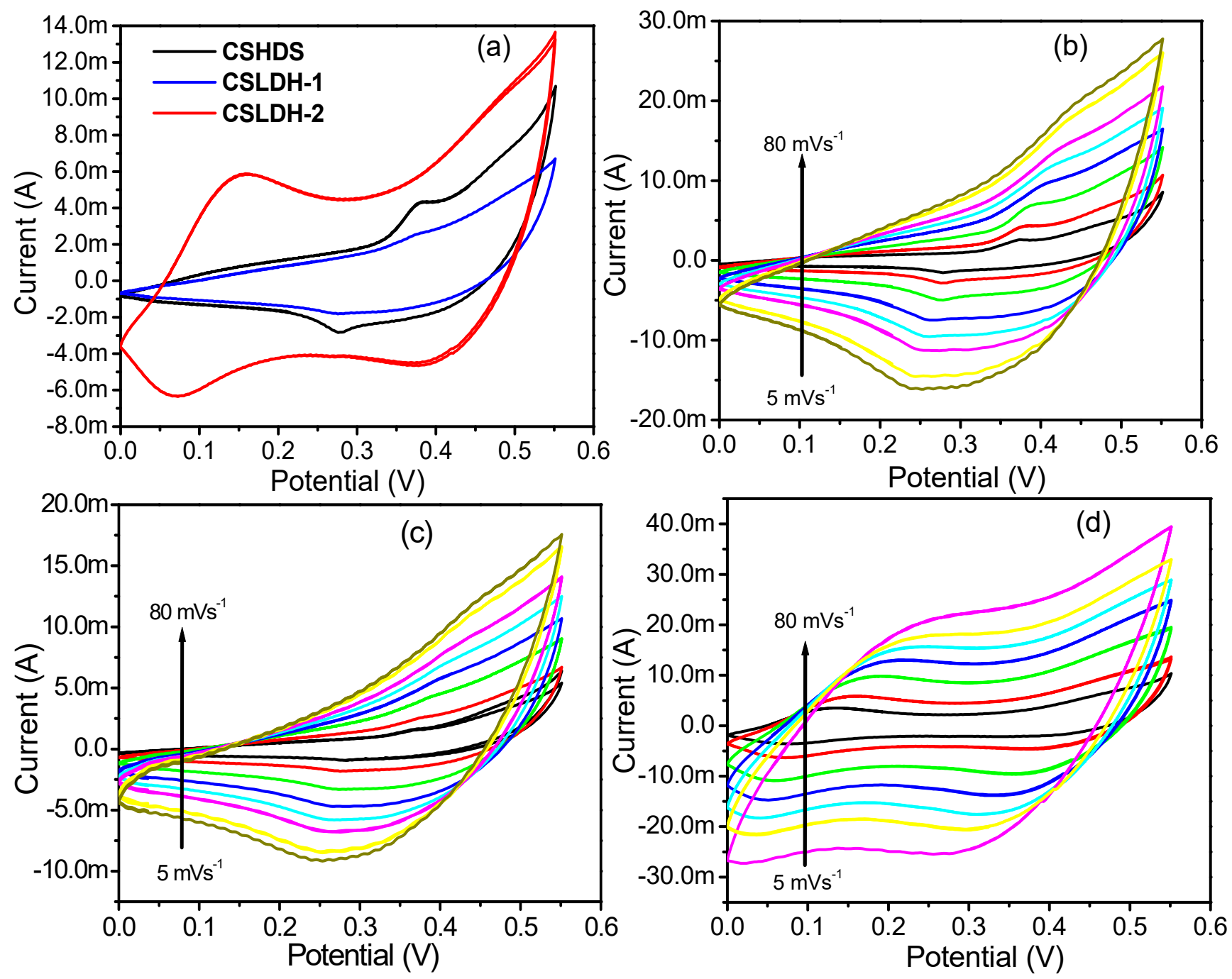

Figure 11. (a) Comparative CV curves of CSHDS, CSLDH-1 and CSLDH-2 at fix scan rate of $10 \mathrm{mVs}^{-1}$; (b) CV curves of CSHDS; (c) CSLDH-1; and (d) CSLDH-2 at different scan rate. 

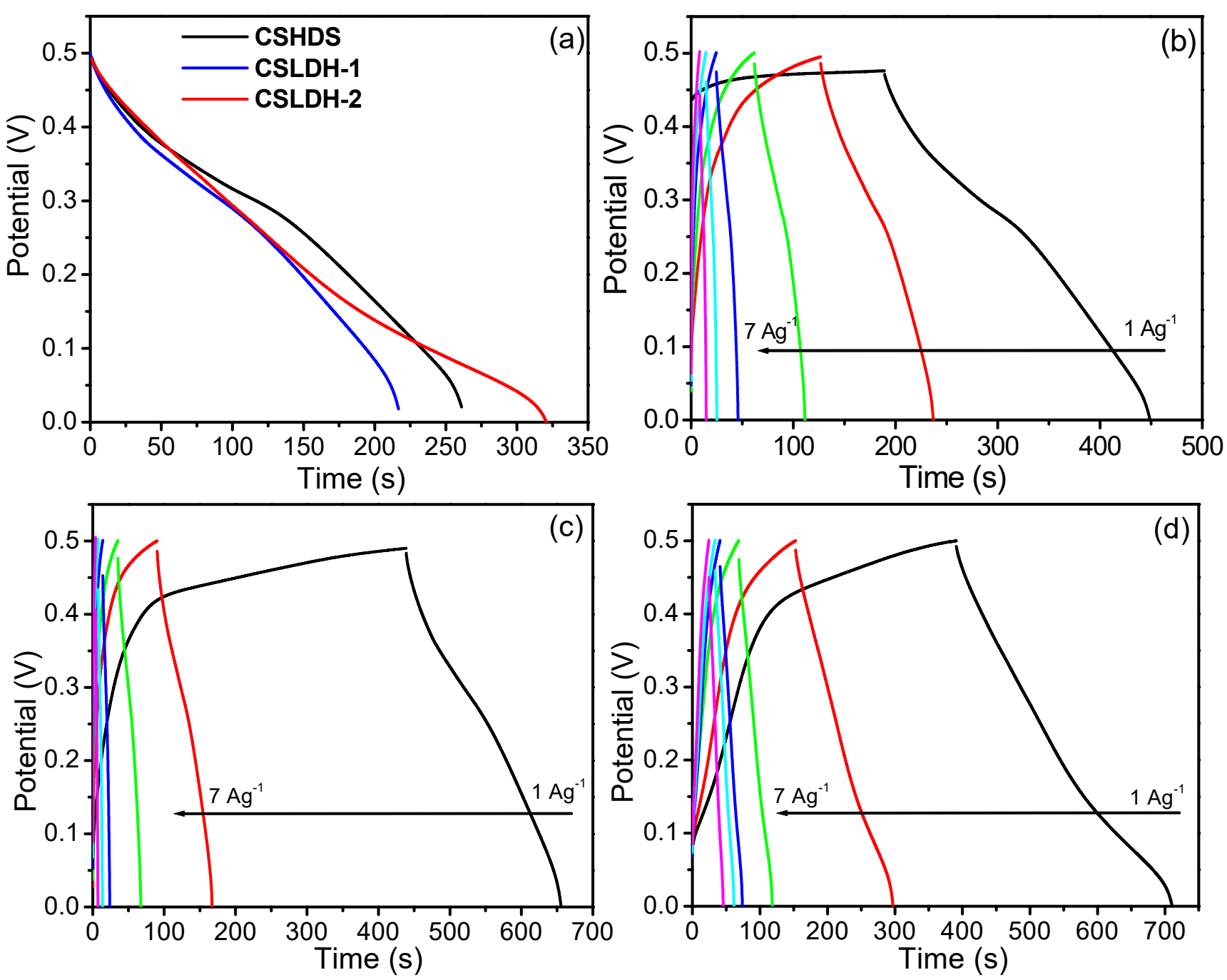

Figure 12. (a) Comparative CD curves of CSHDS, CSLDH-1 and CSLDH-2 fix current density of $1 \mathrm{Ag}^{-1}$; (b), CD curves of CSHDS; (c) CSLDH-1; and (d) CSLDH-2 at different current different current densities.

In this regard, the initial behavior (faradic or non-faradic reaction) and specific capacitance of the electrodes were examined by the $\mathrm{CV}$ analysis in the suitable potential range of $0.0-0.55 \mathrm{~V}$ with numerous scan rates from 5 to $80 \mathrm{mVs}^{-1}$. For the comparative assessment of the CV analysis results, the CSHDS, CSLDH-1 and CSLDH-2 electrodes performed at fixed potential scan rate $\left(10 \mathrm{mVs}^{-1}\right)$ in the potential range of 0.0 to $0.55 \mathrm{~V}$ are shown in Figure 11a. The CV profiles of the CSHDS, CSLDH-1 and CSLDH-2 electrodes show distinct from each other in terms of oxidation (cathodic sweep; positive current) and reduction peaks (anodic sweeps; positive current) during the charging and discharging cycle. All the electrodes revealed the predominant, distinct pair of redox peaks which indicate that the charge storage was majorly from the faradaic pseudocapacitance rather than from the electrochemical double layer capacitor. Specific capacitance is an important parameter for evaluating performance due to its direct link with the energy storage of the pseudocapacitor, which is generally denoted by $\mathrm{E}=1 / 2 \mathrm{CV}^{2}$. Additionally, it is well known that the charges stored change with respect to the area under the CV curves, which are directly proportional to the specific capacitance. It can be found that the integrated area under the CV of CSLDH-2 was larger than that of the CSLDH-1 and CSHDS electrodes, indicating the higher specific capacitance provided by the CSLDH-2 electrode. This enhanced performance of the CSLDH-2 electrode was attributed to synergistic effects between the electric double layer capacitive character of the tin and the pseudocapacitance nature of the cobalt and also indicated that the CSHDS and CSLDH-1 electrodes have poor rate 
performance because of slow charge diffusion rate. Secondly, transformations in nanosize and fibrous morphology provide a larger surface area to volume ratio and better pore size in comparison to the CSLDH-1 and CSHDS electrodes, and have strong effects on the enhanced performance of CSLDH-2 because they can expose more active sites for the intercalation of the ions during electrochemical analysis.

Furthermore, the capacity behavior of the CSHDS, CSLDH-1 and CSLDH-2 electrodes was studied by $\mathrm{CV}$ analysis at different voltage scan rates $\left(10-80 \mathrm{mVs}^{-1}\right)$, as demonstrated in Figure 11. The individual CV profiles displayed clear pairs of oxidation and reduction peaks. In Figure 11b, a pair of redox peaks are observed for the CSHDS electrode with platelike morphology at a scan rate of $5 \mathrm{mVs}^{-1}$, which are assigned to the reversible redox reactions of $\mathrm{Sn}^{2+} / \mathrm{Sn}^{4+}$ and $\mathrm{Co}^{2+} / \mathrm{Co}^{3+}$ transitions associated with $\mathrm{OH}$ anions. At a high scan rate of $80 \mathrm{mVs}^{-1}$, the anodic and cathodic peaks altered, which suggests that this redox reaction was easily reversible and could be used for fast charging/discharging in supercapacitors. An almost similar observation was also found in the CSLDH-1 electrode, which has a dominantly fibrous morphology. Furthermore, the optimized electrode of CSLDH-2, which has one dimensional nanofibrous morphology, shows a predominant redox reaction during anodic and cathodic sweeps in CV.

With the increasing scan rate, the CSLDH-2 electrode seems to have improved in terms of holding the nature of its $\mathrm{CV}$ profile compared to the other electrodes, proposing that the rate capability of this electrode is significantly higher.

On the other hand, a partial contribution from the double layer mechanism is also observed, as evidenced by the small rectangular area that appeared between -0.05 to $0.1 \mathrm{~V}$. Similar to oxide-based electrodes, the capacitance of these electrodes is thought to occur predominantly because of pseudocapacitance mechanism that belongs to the reversible redox mechanism occurring between the electrode and the electrolyte.

In conclusion, the $\mathrm{CV}$ curves of all the electrodes show that the current of the redox peak increases with increasing scan rate. Moreover, from the CV curves, it is observable that the oxidation-reduction peaks are moving towards the higher and lower potentials due to the reinforced electric polarization and feasible kinetic irreversibility of the electrolytic ion on the electrode surface [40]. The potential of the electrodes changes more and more, leading to inadequate redox reactions on the interfaces between the electrode and the electrolyte. Therefore, the pseudocapacitance primarily derived from redox reactions slowly reduces. The material exhibited redox peak in CV curve should not be considered a pseudocapacitor, as the capacitance of the electrode keeps altering over the whole potential window. Therefore, the electrochemical performance of the $\mathrm{Sn} / \mathrm{Co}$ electrodes was measured in terms of the specific capacity instead of specific capacitance [40].

Once the CV analysis was performed to verify the capacity nature, including pseudocapacitance, the galvanostatic charge-discharge measurement was carried out to investigate the charge-discharge performance for all prepared electrodes. For the better applicability of the electrodes, it can be directly evaluated by the charge-discharge performance.

Figure 12a shows the CD curves of the CSHDS, CSLDH-1 and CSLDH-2 at the current density of the $1 \mathrm{Ag}^{-1}$ in potential range of the 0.0 to $0.5 \mathrm{~V}$. Consistent with the outcomes of the CV analysis of these three electrodes, the discharge period of the CSHDS electrode is significantly higher than that of the CSLDH-1 electrode, which has plate morphology. Furthermore, the discharge time considerably increased when the plate morphology completely transformed into a one dimensional morphology. Such enhanced performance in the electrochemical response might be due to high surface-to-volume ratio and electric conductivity, which allows more redox reactions to occur and hence better capacity to be achieved. All the electrodes indicated an analogous behavior over the course of both charge and discharge process. Contrasting with the linear charge-discharge curves which are characteristics of EDLC, the prominent plateau was observed in the discharge curves, which confirmed the faradic reaction for all three electrodes that again confirms that the capacitance is achieved predominantly from the faradic reaction mechanism and thus is in good agreement with $\mathrm{CV}$ observation. To further examine the electrochemical behavior, 
the charge-discharge analysis was performed at various current densities from 1-7 $\mathrm{Ag}^{-1}$. All the electrodes show a semi-symmetric $C D$ curve which demonstrates rapid response and excellent electrochemical reversibility and confirms the faradic behavior of the electrodes $[41,42]$. The CSLDH-2 electrode shows higher CD time over the entire range of current density as compared to the other two electrodes. These findings are well matched with the results from the $\mathrm{CV}$ analysis. The obtained charge-discharge results were further applied to determine the specific capacitance values using following equation:

$$
\mathrm{C}=\mathrm{I} \times \Delta \mathrm{t} / \Delta \mathrm{V} \times \mathrm{w},
$$

where $C$ is the specific capacitance, $I$ is stand for the discharge current density, $\Delta t$ is the charge-discharge time, $\Delta \mathrm{V}$ is the working potential window, and $\mathrm{w}$ is the mass of active material which present on the current collector.

The calculated specific capacitance of the CSLDH-2 electrode is $658 \mathrm{Fg}^{-1}$ at current density of $1 \mathrm{Ag}^{-1}$ which is higher than CSHDS (520 Fg-1) and CSLDH-1 $\left(434 \mathrm{Fg}^{-1}\right)$ electrodes. The higher specific capacitance of the CSLDH-2 electrode is due to the nanosize of the fibrous morphology. Figure $12 \mathrm{~d}$ represents the CD curves of the CSLDH-2 electrode, whereas Figures $12 \mathrm{c}$ and $11 \mathrm{~b}$ show the CD curves of the CSLDH-1 and CSHDS electrodes, respectively, at current densities ranging from $1 \mathrm{Ag}^{-1}$ to $7 \mathrm{Ag}^{-1}$. The calculated specific capacitance of the CSLDH-1 and CSHDS electrodes at different current densities of 1, 2, 3, 4, 5 and $7 \mathrm{Ag}^{-1}$ were $658,584,330,312,290,280 \mathrm{Fg}^{-1}$, respectively. For the CSLDH-1 electrode, the estimated specific capacitances were 520, 444, 300, 176, 120, $98 \mathrm{Fg}^{-1}$. Similarly, the specific capacitances of CSHDS electrode were $434,312,210,96,57,42 \mathrm{Fg}^{-1}$, respectively. Among all three of the electrodes, CSLDH-2 electrode exhibited higher specific capacitance because of its nanofibrous morphology, which provides higher surface area and more active sites for the electrolyte intercalation-deintercalation during the $\mathrm{CD}$ process and maximizes the utilization of the CSLDH-2 electrode.

Figure 13a represents the specific capacitance of the CSHDS, CSLDH-1 and CSLDH-2 at different current densities. From Figure 13a, it is clearly demonstrated that with an increase in the current densities, the specific capacitance decreased for all three electrodes. The highest specific capacitance (e.g., $658 \mathrm{Fg}^{-1}$ at $1 \mathrm{Ag}^{-1}$ current density) was observed in the complete range of current density with an electrode prepared by an optimal percentage/quantity of the precursor, which is a CSLDH-2 electrode. Moreover, the specific capacitance slowly decreased with an increase in the operating current density, and then demonstrated steeper drops including the other two electrodes. This is due to low intercalation of the electrolyte ions into the bulk of the electrode, which then does not have much time to take a part in the reaction with the electrolyte at a higher current density. The specific capacitance of the nanofibrous CSLDH-2 electrode is higher than the previously reported cobalt-tin composite electrodes. For example, nanoparticle of $\mathrm{CoSn}(\mathrm{OH})_{6}$ showed higher specific capacitance of $450 \mathrm{Fg}^{-1}$, and the $\mathrm{SnO}_{2} / \mathrm{Co}_{3} \mathrm{O}_{4}-\mathrm{C}$ composite exhibited higher specific capacitance of $177 \mathrm{Fg}^{-1}[43,44]$. The comparative performances, including the different concentrations of the electrolytes [45-49], are also summarized in Table 2.

Table 2. Comparative performances including the different concentration of the electrolytes.

\begin{tabular}{ccccc}
\hline $\begin{array}{l}\text { Electrode } \\
\text { Material }\end{array}$ & Electrolyte & Current Density & Capacitance & References \\
\hline $\mathrm{CoV}_{2} \mathrm{O}_{6}$ & $2 \mathrm{M} \mathrm{KOH}$ & $1 \mathrm{Ag}^{-1}$ & $223 \mathrm{Fg}^{-1}$ & 45 \\
$\mathrm{Co}_{3} \mathrm{~V}_{2} \mathrm{O}_{8}$ & $3 \mathrm{M} \mathrm{KOH}$ & $0.5 \mathrm{Ag}^{-1}$ & $739 \mathrm{Fg}^{-1}$ & 46 \\
$\mathrm{Co}_{2} \mathrm{P}$ & $6 \mathrm{M} \mathrm{KOH}$ & $1 \mathrm{Ag}^{-1}$ & $416 \mathrm{Fg}^{-1}$ & 47 \\
$\mathrm{CoWO}_{4}$ & $2 \mathrm{M} \mathrm{KOH}$ & $1 \mathrm{Ag}^{-1}$ & $764 \mathrm{Fg}^{-1}$ & 48 \\
$\mathrm{Co}_{11}\left(\mathrm{HPO}_{3}\right)_{8}(\mathrm{OH})_{6}$ & $3 \mathrm{M} \mathrm{KOH}$ & $1.25 \mathrm{Ag}^{-1}$ & $312 \mathrm{Fg}^{-1}$ & 49 \\
$\mathrm{CSLDH}_{-2}$ & $2 \mathrm{M} \mathrm{KOH}$ & $1 \mathrm{Ag}^{-1}$ & $658 \mathrm{Fg}^{-1}$ & Present Work \\
\hline
\end{tabular}



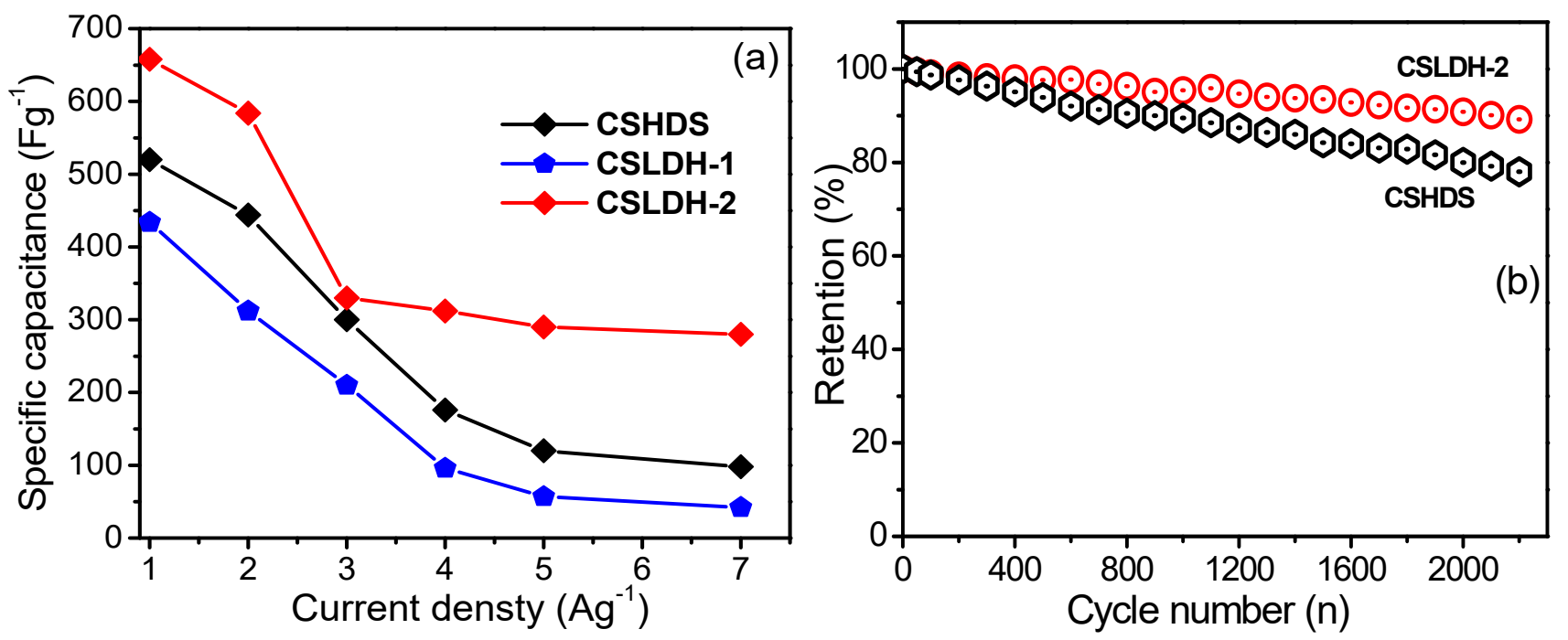

Figure 13. (a) Calculated specific capacitance CSHDS, CSLDH-1 and CSLDH-2 at different current densities in $2 \mathrm{M} \mathrm{KOH}$ aqueous electrolyte and (b) Cyclic stability of CSHDS and CSLDH-2 at $4 \mathrm{Ag}^{-1}$ over 2200 cycles.

The stability of the electrode is one of the most important issues in energy storage applications. All of the earlier electrochemical results based on CV, GCD and rate capability clearly indicate that the CSLDH-2, which has one dimensional nanofibrous morphology, produced the most improved capacitance. The cyclic stability of the optimized CSLDH-2 electrode was examined by the continuous $\mathrm{CD}$ analysis test at $4 \mathrm{Ag}^{-1}$ current density over the 2200 cycles. As shown in Figure 13b, the nanofibrous CSLDH-2 electrode showed excellent cyclic stability $\left(4 \mathrm{Ag}^{-1}\right)$ up to the 2200 cycles and retained around $89 \%$ of the specific capacitance as compared to the CSHDS electrode. This better performance of the CSLDH-2 demonstrates that it is the presence of the cobalt filler in the CSLDH-2 electrode which helps to stabilize the overall structure of the nanocomposite during the charge-discharge process. The electrochemical performance of the CSLDH-2 electrode is comparatively higher than the other two electrodes (CSHDS and CSLDH-1). In addition, the retention of the CSLDH-2 electrode highlights its excellent cycling stability and suggests the high reversibility and excellent electrochemical stability of the electrode. However, the obtained capacitance retention is gradually decreased with the increase in the chargedischarge process, which might be attributed to the electrolyte ions blocking the pores of the electrode materials; in the present case, the electrolyte ions may be trapped in the layers of CSLDH-2 and barred from contributing to further electrochemical redox reaction processes in an aqueous electrolyte. Additionally, the Sn/Co might undergo structural degradation in the electrolyte during the charge-discharge process. Hence, the significant deficiency of capacitance that we noticed might be attributed to the unwanted electrochemical redox reaction and structural instability of the electrode in aqueous electrolyte. Efforts are still being made to upgrade the capacitance performance by introducing carbonaceous materials, such as graphene and other carbon-based material with different morphology, in work in the near future.

\section{Conclusions}

In this study, three different morphologies of Sn/Co nanolayered structures have been successfully fabricated via host-guest interactions. By intercalation reactions, the guests (cyanate and nitrate anions) were used as pillars for the nanolayers of both cobalt and tin to build nanolayered structures. By using divalent tin combined with cobalt, the plate morphology of Sn/Co HDS (CSHDS) was formed through nanolayered structures. In the case of using tetravalent tin, the plate structure started its transformation to nanofibers by forming a plate-nanofibrous morphology of Sn/Co LDH (CSLDH-1) through dual intercalation process for both cyanate and nitrate anions. This transformation could be 
explained by the repulsion forces between the cyanate anions and nitrate anions in the confined space among the cationic nanolayers of $\mathrm{Sn} / \mathrm{Co}$. These forces led to the curvature of the nanolayers, forming nanofibers. By changing the percentage of tetravalent tin, the repulsive forces increased to form a nanofibrous morphology for Sn/Co LDH (CSLDH-2). This nanofibrous morphology was favorable for obtaining high specific capacitance and excellent rate stability. In comparison to plate morphology (CSHDS) and plate-fibers (CSLDH-1), the nanofibers (CSLDH-2) electrode showed improved specific capacitance $\left(658 \mathrm{Fg}^{-1}\right)$ and excellent rate stability $(89 \%)$ which can be attributed to the synergistic effects between the electric double layer capacitive character of the tin and the pseudocapacitance nature of the cobalt, and also indicates that the other morphologies of CSHDS and CSLDH-1 electrodes have poor rate performance due to their slow charge diffusion rates. Secondly, as compared to platelike morphology, nanosize and fibrous morphologies provide larger surface area and better pore size as compared to the CSLDH-1 and CSHDS electrodes and can expose more active sites for the intercalation of the ions during electrochemical analysis.

Author Contributions: Conceptualization, O.S.; Data curation, O.S. and S.A.A.; Formal analysis, S.A.A. and A.A.; Funding acquisition, O.S.; Investigation, O.S. and A.A.; Methodology, S.A.A.; Project administration, O.S.; Resources, S.A.A.; Software, A.A.; Supervision, O.S.; Validation, A.A.; Visualization, A.A.; Writing—original draft, O.S. and S.A.A.; Writing—review and editing, O.S. and S.A.A. All authors have read and agreed to the published version of the manuscript.

Funding: This research was funded by the Deanship of Scientific Research in King Faisal University (Saudi Arabia), grant number 1811006 and the APC was funded by the same grant number 1811006 .

Institutional Review Board Statement: Not applicable.

Informed Consent Statement: Not applicable.

Data Availability Statement: Data available in a publicly accessible repository.

Acknowledgments: The authors acknowledge the Deanship of Scientific Research at King Faisal University for the financial support under the Research Group Support Track (Grant No.1811006).

Conflicts of Interest: The authors declare no conflict of interest.

\section{References}

1. Chen, H.; Shen, Z.; Pan, Z.; Kou, Z.; Liu, X.; Zhang, H.; Gu, Q.; Guan, C.; Wang, J. Hierarchical micro-nano sheet arrays of nickel-cobalt double hydroxides for high-rate Ni-Zn batteries. Adv. Sci. 2019, 6, 1802002. [CrossRef] [PubMed]

2. Chen, H.; Hu, L.; Chen, M.; Yan, Y.; Wu, L. Nickel-cobalt layered double hydroxide nanosheets for high-performance supercapacitor electrode materials. Adv. Funct. Mater. 2014, 24, 934-942. [CrossRef]

3. Zhou, J.J.; Li, Q.; Chen, C.; Li, Y.L.; Tao, K.; Han, L. $\mathrm{Co}_{3} \mathrm{O}_{4} @ \mathrm{CoNi}-\mathrm{LDH}$ core/shell nanosheet arrays for high-performance battery-type supercapacitors. Chem. Eng. J. 2018, 350, 551-558. [CrossRef]

4. Cao, F.; Gan, M.; Ma, L.; Li, X.; Yan, F.; Ye, M.; Zhai, Y.; Zhou, Y. Hierarchical sheet like Ni-Co layered double hydroxide derived from a MOF template for high performance supercapacitors. Synthetic. Met. 2017, 234, 154-160. [CrossRef]

5. Maki, H.; Inoue, M.; Mizuhata, M. Charge transfer resistance reduction by the interlayer distance expansion of Ni-Al layered double hydroxide for nickel metal hydride battery anode. Electrochim. Acta. 2018, 270, 395-401. [CrossRef]

6. Kim, M.; Park, T.; Wang, C.; Tang, J.; Lim, H.; Hossain, M.S.A.; Konarova, M.; Yi, J.W.; Na, J.; Kim, J.; et al. Tailored Nanoarchitecturing of Microporous ZIF-8 to Hierarchically Porous Double-Shell Carbons and Their Intrinsic Electrochemical Property. ACS Appl. Mater. Interfaces 2020, 12, 34065-34073. [CrossRef]

7. Yadav, H.M.; Nath, N.C.D.; Kim, J.; Shinde, S.K.; Ramesh, S.; Hossain, F.; Ibukun, O.; Lee, J. Nickel-Graphene Nanoplatelet Deposited on Carbon Fiber as Binder-Free Electrode for Electrochemical Supercapacitor Application. Polymers 2020, $12,1666$. [CrossRef]

8. Kim, M.; Lim, H.; Wang, C.; Kani, K.; Kwon, G.; You, J.; Park, H.; Alshehri, A.A.; Alghamidi, Y.G.; Alzahrani, K.A.; et al. Core-shell structured metal-organic framework-derived carbon with redox-active polydopamine nanothin film. Mater. Lett. 2019, 253, 178-182. [CrossRef]

9. Wang, Z.; Xu, X.; Kim, J.; Malgras, V.; Mo, R.; Li, C.; Lin, Y.; Tan, H.; Tang, J.; Pan, L.; et al. Nanoarchitectured metal-organic framework/polypyrrole hybrids for brackish water desalination using capacitive deionization. Mater. Horiz. 2019, 6, 1433-1437. [CrossRef]

10. Tanaka, S.; Kaneti, Y.V.; Septiani, N.L.W.; Dou, S.X.; Bando, Y.; Hossain, M.S.A.; Kim, J.; Yamauchi, Y. A Review on Iron Oxide-Based Nanoarchitectures for Biomedical, Energy Storage, and Environmental Applications. Small Methods 2019, 3, 1800512. [CrossRef] 
11. Saddique, J.; Cheng, X.; Shi, H.; Wu, R.; Zhang, Y. High-Performance Ni-Co Sulfide Nanosheet-Nanotubes Grown on Ni Foam as a Binder Free Electrode for Supercapacitors. Appl. Sci. 2019, 9, 3082. [CrossRef]

12. Chong, B.; Azman, N.; Abdah, M.; Sulaiman, Y. Supercapacitive Performance of N-Doped Graphene $/ \mathrm{Mn}_{3} \mathrm{O}_{4} / \mathrm{Fe}_{3} \mathrm{O}_{4}$ as an Electrode Material. Appl. Sci. 2019, 9, 1040. [CrossRef]

13. Saber, O.; Aljaafari, A.; Osama, A.; Alshoaibi, A. Optimization Conditions for Crystal Growth of Novel Nanolayers, Nanohybrids and Nanocomposites Based on Cobalt, Zirconium, Titanium and Silicon. Chem. Select 2019, 4, 580-588. [CrossRef]

14. Saber, O.; Aljaafari, A.; Asiri, S.; Batoo, K.M. Designing Magnetic Layered Double Hydroxides and Two-Dimensional Magnetic Nano-Nets of Cobalt Ferrite through a Novel Approach. Appl. Sci. 2018, 8, 2099. [CrossRef]

15. Saber, O.; Ansari, S.A.; Alshoaibi, A. Development of Ti/Ni Nanolayered Structures to Be a New Candidate for Energy Storage Applications. Appl. Sci. 2020, 10, 6935. [CrossRef]

16. Kaassis, A.Y.A.; Xu, S.M.; Guan, S.; Evans, D.G.; Wei, M.; Williamsm, G.R. Hydroxy double salts loaded with bioactive ions: Synthesis, intercalation mechanisms, and functional performance. J. Solid State Chem. 2016, 238, 129-138. [CrossRef]

17. Thomas, N. Mechanochemical synthesis of layered hydroxy salts. Mater. Res. Bull. 2012, 47, 3568-3572. [CrossRef]

18. Metwally, S.M.; Saber, O.; Ibrahim, S.S.; Al Naim, A.F. Synthesis and characterization of copper hydroxy nitrate salt $\left(\mathrm{Cu}_{2}(\mathrm{OH})_{3} \mathrm{NO}_{3}\right)$ : Effect of gamma radiation absorbed doses on thermal stability. Mater. Express 2019, 9, 545-552. [CrossRef]

19. Liu, L.; Liu, A.; Xu, Y.; Yu, H.; Yang, F.; Wang, J.; Zeng, Z.; Deng, S. Agglomerated nickel-cobalt layered double hydroxide nanosheets on reduced graphene oxide clusters as efficient asymmetric supercapacitor electrodes. J. Mater. Res. 2020, 35, 1205-1213. [CrossRef]

20. Liang, H.; Lin, J.; Jia, H.; Chen, S.; Qi, J.; Cao, J.; Lin, T.; Fei, W.; Feng, J. Hierarchical NiCo LDH@NiOOH core-shell heterostructure on carbon fiber cloth as battery-like electrode for supercapacitor. J. Power Sources 2018, 378, 248-254. [CrossRef]

21. He, X.; Liu, Q.; Liu, J.; Li, R.; Zhang, H.; Chen, R.; Wang, J. Hierarchical $\mathrm{NiCo}_{2} \mathrm{O}_{4}-\mathrm{NiCoAl}$ layered double hydroxide core/shell nanoforest arrays as advanced electrodes for high performance asymmetric supercapacitors. J. Alloys. Compd. 2017, 724, 130-138. [CrossRef]

22. Yu, Y.; Tan, Y.; Zhang, H.; Yang, B.; Yuan, L.; Shen, X.; Hu, X. Hybrid Sn-Co binary oxide nanosheets grown on carbon paper as the supercapacitor electrode materials. J. Alloys Compd. 2020, 814, 152199. [CrossRef]

23. Wang, G.; Li, Y.; Xu, L.; Jin, Z.; Wang, Y. Facile synthesis of difunctional NiV LDH-ZIF-67 p-n junction: Serve as prominent photocatalyst for hydrogen evolution and supercapacitor electrode as well. Renew. Energy 2020, 162, 535-549. [CrossRef]

24. Ziba, A.; Pacuła, A.; Serwicka, E.M.; Drelinkiewicz, A. Transesterification of Triglycerides with Methanol over Thermally Treated $\mathrm{Zn}_{5}(\mathrm{OH})_{8}\left(\mathrm{NO}_{3}\right)_{2} .2 \mathrm{H}_{2} \mathrm{O}$ Salt. Fuel 2010, 89, 1961-1972. [CrossRef]

25. Delorme, F.; Seron, A.; Giovannelli, F.; Beny, C.; Jean-Prost, V.; Martineau, D. Synthesis and anion exchange properties of a Zn/Co double hydroxide salt. Solid State Ion. 2011, 187, 93-97. [CrossRef]

26. Saber, O.; Shaalan, N.M.; Osama, A.; Alshoaibi, A. Development of the Morphology and the Band Gap Energy of Co-Si Nanofibers by Inserting Zirconium and Titanium with Dual Anions Intercalation Process. Appl. Sci. 2019, 9, 4775. [CrossRef]

27. Fang, S.; Li, J.; Xiang, C.; Zou, Y.; Xu, F.; Sun, L.; Zhang, J. Anchoring sea urchin-like cobalt-nickel carbonate hydroxide on 3D carbon sponge for electrochemical energy storage. J. Alloys Compd. 2020, 845, 156024-156034. [CrossRef]

28. Kolinjavadi, M.; Bhojaraj; Rajamathi, M. Nickel-zinc hydroxy salts with varying amounts of octahedral $\mathrm{Zn}^{2+}$ : Trends in stability and selectivity in anion exchange reaction. J. Chem. Sci. 2019, 131, 112-118. [CrossRef]

29. Bull, R.M.R.; Markland, C.; Williams, G.R.; O'Hare, D. Hydroxy double salts as versatile storage and delivery matrices. J. Mater. Chem. 2016, 238, 129-138. [CrossRef]

30. You, Y.; Zhao, H.; Vance, G.F. Hybrid Organic-Inorganic Derivatives of Layered Double Hydroxides and Dodecylbenzene sulfonate: Preparation and Adsorption Characteristics. J. Mater. Chem. 2002, 12, 907-912. [CrossRef]

31. Bao, W.; Tian, H.; Jiang, Y.; Zhu, K.; Zhang, R.; Tan, Y.; Li, W.; Yu, Z.; Wang, L. Controlled preparation of $\mathrm{Ni}^{-\mathrm{Al}} \mathrm{LDH}^{-\mathrm{NO}} 3$ by a dual-anion intercalating process for supercapacitors. Ionics 2019, 25, 3859-3866. [CrossRef]

32. Kotb, H.M.; Saber, O.; Ahmad, M.M. Colossal relative permittivity and low dielectric loss in $\mathrm{BaFe}_{0.5} \mathrm{Nb}_{0.5} \mathrm{O}_{3}$ ceramics prepared by spark plasma sintering. Results Phys. 2020, 19, 103607. [CrossRef]

33. Miyata, S. The syntheses of hydrotalcitelike compounds and their structures and physicochemical properties. Clays Clay Miner. 1995, 23, 369-375. [CrossRef]

34. Xu, Z.P.; Zeng, H.C. Decomposition Pathways of Hydrotalcite-like Compounds $\mathrm{Mg}_{1-\mathrm{x}} \mathrm{Al}_{\mathrm{x}}(\mathrm{OH})_{2}\left(\mathrm{NO}_{3}\right) \mathrm{x} . \mathrm{nH}_{2} \mathrm{O}$ as a Continuous Function of Nitrate Anions. Chem. Mater. 2001, 13, 4564-4572. [CrossRef]

35. Nakamoto, N. Infrared and Raman Spectra of Inorganic and Coordination Compounds, 4th ed.; Wiley: New York, NY, USA, 1986.

36. Li, X.; Du, D.; Zhang, Y.; Xing, W.; Xue, Q.; Yan, Z. Layered double hydroxides toward high performance supercapacitors. J. Mater. Chem. A 2017, 5, 15460-15485. [CrossRef]

37. Perez-Ramirez, J.; Mul, G.; Kapteijin, F.; Moulijn, J.A. In situ investigation of the thermal decomposition of Co-Al hydrotalcite in different atmospheres. J. Mater. Chem. 2001, 11, 821-832. [CrossRef]

38. Magri, V.R.; Duarte, A.; Perotti, G.F.; Constantino, V.R.L. Investigation of Thermal Behavior of Layered Double Hydroxides Intercalated with Carboxymethylcellulose Aiming Bio-Carbon Based Nanocomposites. Chem. Eng. 2019, 3, 55. [CrossRef]

39. Constantino, V.R.L.; Pinnavaia, T.J. Basic Properties of $\mathrm{Mg}^{2+}{ }_{1-\mathrm{x}} \mathrm{Al}^{3+}{ }_{\mathrm{x}}$ Layered Double Hydroxides Intercalated by Carbonate, Hydroxide, Chloride, and Sulfate Anions. Inorg. Chem. 1995, 34, 883-892. [CrossRef] 
40. Omar, F.S.; Numan, A.; Duraisamy, N.; Ramly, M.M.; Ramesh, K.; Ramesh, S. Binary composite of polyaniline/copper cobaltite for high performance asymmetric supercapacitor application. Electrochim. Acta 2017, 227, 41-48. [CrossRef]

41. Gu, C.D.; Ge, X.; Wang, X.L.; Tu, J.P. Cation-anion double hydrolysis derived layered single metal hydroxide superstructures for boosted super capacitive energy storage. J. Mater. Chem. A 2015, 3, 14228-14238. [CrossRef]

42. Wang, T.; Hao, Q.; Liu, J.; Zhao, J.; Bell, J.; Wang, H. High capacitive amorphous barium nickel phosphate nanofibers for electrochemical energy storage. RSC Adv. 2016, 6, 45986-45992. [CrossRef]

43. Premkumara, V.K.; Sivakumar, G. Hydrothermally Synthesized $\mathrm{CoSn}(\mathrm{OH})_{6}$ Nanoparticles for Electrochemical Performance. Jordan J. Phys. 2018, 11, 131-135.

44. Pal, B.; Krishnan, S.G.; Vijayan, B.L.; Harilal, M.; Yang, C.; Ezema, F.I.; Yusoff, M.M.; Jose, R.R. In situ encapsulation of tin oxide and cobalt oxide composite in porous carbon for high-performance energy storage applications. J. Electroanal. Chem. 2018, 817, 217-225. [CrossRef]

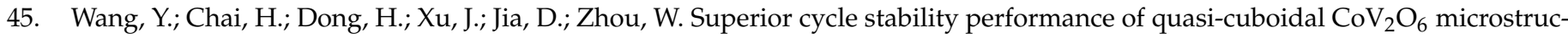
tures as electrode material for supercapacitors. ACS Appl. Mater. Interfaces 2016, 8, 27291-27297. [CrossRef] [PubMed]

46. Zhang, Y.; Liu, Y.; Chen, J.; Guo, Q.; Wang, T.; Pang, H. Cobalt vanadium oxide thin nanoplates: Primary electrochemical capacitor application. Sci. Rep. 2014, 4, 5687-5691. [CrossRef] [PubMed]

47. Chen, X.; Cheng, M.; Chen, D.; Wang, R. Shape-controlled synthesis of Co2P nanostructures and their application in supercapacitors. ACS Appl. Mater. Interfaces 2016, 8, 3892-3900. [CrossRef]

48. He, G.; Li, J.; Li, W.; Li, B.; Noor, N.; Xu, K.; Hu, J.; Parkin, I.P. One pot synthesis of nickel foam supported self-assembly of $\mathrm{NiWO}_{4}$ and $\mathrm{CoWO}_{4}$ nanostructures that act as high performance electrochemical capacitor electrodes. J. Mater. Chem. A 2015, 3, 14272-14278. [CrossRef]

49. Pang, H.; Liu, Y.; Li, J.; Ma, Y.; Li, G.; Ai, Y.; Chen, J.; Zhang, J.; Zheng, H. Cobalt phosphite microarchitectures assembled by ultralong nanoribbons and their application as effective electrochemical capacitor electrode materials. Nanoscale 2013, 5, 503-507. [PubMed] 